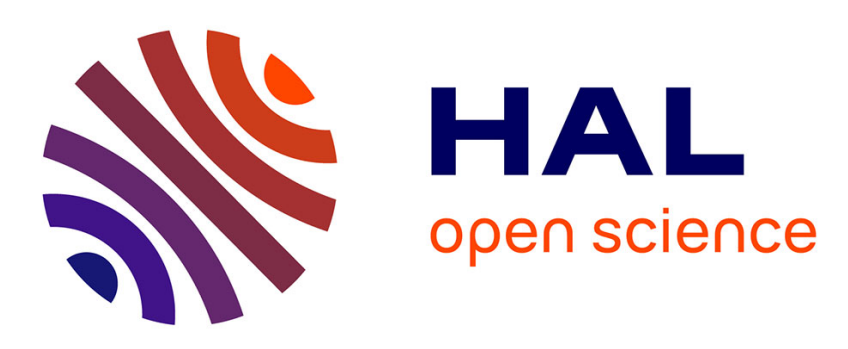

\title{
Organic Rankine Cycle for Vehicles: Control Design and Experimental Results
}

\author{
Johan Peralez, Madiha Nadri, Pascal Dufour, Paolino Tona, Antonio
}

Sciarretta

\section{- To cite this version: \\ Johan Peralez, Madiha Nadri, Pascal Dufour, Paolino Tona, Antonio Sciarretta. Organic Rankine Cycle for Vehicles: Control Design and Experimental Results. IEEE Transactions on Control Systems Technology, 2017, 25 (3), pp.952 - 965. 10.1109/TCST.2016.2574760 . hal-01443948}

\section{HAL Id: hal-01443948 \\ https: / hal-ifp.archives-ouvertes.fr/hal-01443948}

Submitted on 23 Jan 2017

HAL is a multi-disciplinary open access archive for the deposit and dissemination of scientific research documents, whether they are published or not. The documents may come from teaching and research institutions in France or abroad, or from public or private research centers.
L'archive ouverte pluridisciplinaire HAL, est destinée au dépôt et à la diffusion de documents scientifiques de niveau recherche, publiés ou non, émanant des établissements d'enseignement et de recherche français ou étrangers, des laboratoires publics ou privés. 


\title{
Organic Rankine Cycle for Vehicles: Control Design and Experimental Results
}

\author{
Johan Peralez, Madiha Nadri, Pascal Dufour, Paolino Tona, and Antonio Sciarretta
}

\begin{abstract}
The system considered here is an organic Rankine cycle for recovering waste heat from a heavy-duty diesel engine. Because of the highly transient conditions these systems are subject to, control plays a fundamental role to enable the viability and efficiency of those systems. In this context, this paper investigates the problem of control design for superheating $(\mathbf{S H})$ and pressure at evaporator outlet. Based on a moving boundary heat exchanger model, a first controller, which consists of a dynamic feedforward combined to a gain-scheduled PID, is implemented on the pump speed to maintain the SH close to the set-point value. Experimental results illustrate the enhanced performance in terms of disturbance rejection. Then, a second controller based on nonlinear state estimation is proposed. This is a nonlinear feedback law, which allows to adjust the evaporating pressure to time-varying demand with a good accuracy.
\end{abstract}

Index Terms-Control design, feedforward, heavy-duty vehicles, observer, Rankine cycle, waste heat recovery (WHR).

\section{INTRODUCTION}

$\mathbf{I}$ $\mathrm{N}$ RECENT years, growing awareness of environmental and energy issues has steadily driven research and innovation in the automotive sector. Internal combustion engines (ICEs) are now much more energy efficient, thanks, in particular, to the introduction of new architectures (turbocharging and gasoline direct injection) and to the development of more and more efficient engine control systems. However, despite these significant advances in technology, efficiency of ICE remains limited. Thus, even a modern engine cannot convert more than $50 \%$ of fuel energy into useful work. The remaining portion is lost through coolants and exhaust gases [1].

A potential solution to recover this waste heat exists, especially from the heat sources with the highest temperature levels: namely, the tailpipe exhaust gases and the exhaust

Manuscript received June 13, 2015; revised February 1, 2016; accepted April 28, 2016. Manuscript received in final form May 25, 2016. Recommended by Associate Editor S. Di Cairano.

J. Peralez is with the Université de Lyon, Lyon 69622, France, also with Université Claude Bernard Lyon 1, Villeurbanne 69100, France, and also with the Centre National de la Recherche Scientifique, Laboratoire d'Automatique et de Génie des Procédés, Villeurbanne 69622, France, and also with the Control, Signal and System Department, IFP Energies Nouvelles, Rueil-Malmaison 92852, France (e-mail: johan.peralez@gmail.com).

M. Nadri and P. Dufour are with the Université de Lyon, Lyon 69622 France, also with Université Claude Bernard Lyon 1, Villeurbanne 69100, France, and also with the Centre National de la Recherche Scientifique, Laboratoire d'Automatique et de Génie des Procédés, Villeurbanne 69622, France (e-mail: nadri@lagep.univ-lyon1.fr; dufour@lagep.univ-lyon1.fr).

P. Tona and A. Sciarretta are with the Control, Signal and System Department, IFP Energies Nouvelles, Rueil-Malmaison 92852, France (e-mail: paolino.tona@ifp.fr; antonio.sciarretta@ifp.fr).

Color versions of one or more of the figures in this paper are available online at http://ieeexplore.ieee.org.

Digital Object Identifier 10.1109/TCST.2016.2574760

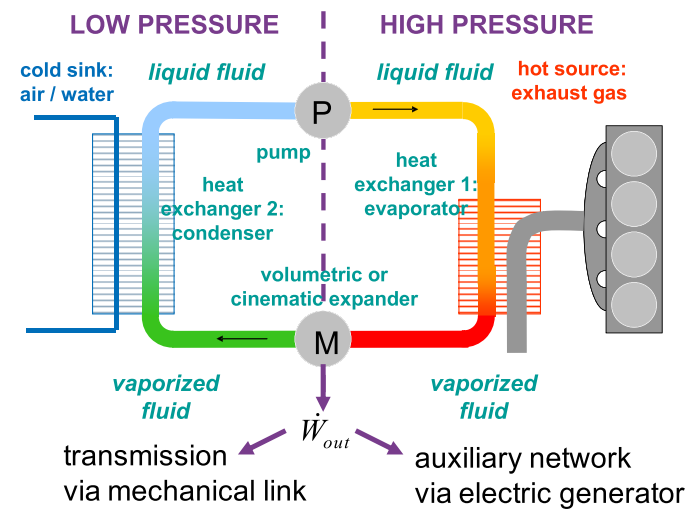

Fig. 1. Rankine WHR system layout for automotive application.

gas recirculation circuit, when present. Among the waste heat recovery (WHR) technologies, compounding the engine with a Rankine bottoming cycle has been widely considered as the most promising solution [1].

Rankine systems for WHR in vehicles are based on the same principle also used for electricity production in most power plants. A pump circulates a working fluid in a closed loop where an external source supplies heat, via a heat exchanger (or a series of exchangers). Vaporized fluid expands in a turbine or an expander to produce mechanical power. Vapor is then cooled by a condenser, which transfers heat to an external cold sink.

Typically, Rankine cycle-based WHR systems for transport applications can be represented as in Fig. 1. The major differences with stationary applications lie with the strongly transient behavior of the hot source and with the limited cooling potential on board. Both these differences depend on the driving conditions of the vehicle.

To be viable, these systems must be lightweight and compact. Thus, heating, vaporization, and superheating $(\mathrm{SH})$ of the fluid usually take place in a single heat exchanger: the evaporator. In most cases, Rankine systems for automotive applications are designed to produce electricity via a generator connected to the auxiliary network and/or an energy storage system, although produced mechanical power can be used directly via a mechanical connection to the transmission, as in [2].

\section{A. Motivation}

The WHR systems based on the Rankine thermodynamic cycle have been the focus of intensive research for road vehicles over recent years. For example, BMW [3], [4], 
Honda [5], and Ford [6] worked on this topic for cars, and Cummins [7], Caterpillar [8], Daimler Trucks [9], and Volvo [10] for trucks. The interest of manufacturers is justified by announced reductions in fuel consumption ranging from 5 to $10 \%$ depending on the system and the driving cycle [11].

As reported in [12], which presents a state of the art on organic Rankine cycle (ORC) for ICE, most of the research papers are dedicated to design issues (structure, components, and working fluid) and to potential assessment (good examples are [13]-[15]). In addition, although control plays a fundamental role to enable viability and energy efficiency of Rankine cycle WHR systems for automotive applications, papers on control issues are surprisingly a few in numbers.

Despite the development of several Rankine system prototypes for road transport, with a few of them even making their way to demo vehicles, it is still unclear how viable and efficient these systems can be in the real-world applications. In practice, these systems often struggle to attain satisfactory performance over a broad range of operating (transient) conditions. Eventually, if the heat recovery system has to be shut down too often and/or it takes too long to attain power production conditions, expected gains will vanish.

In this context, controlling the working fluid state (namely, $\mathrm{SH}$ and pressure) at the evaporator outlet is a key issue when controlling an ORC system, as cycle efficiency and system safety depend on it. This is the focus of this paper.

\section{B. Related Work}

In the (scarce) publications for such applications, including experimental results, the authors systematically put forward the difficulty of controlling the working fluid state ( $\mathrm{SH}$ and pressure) at the evaporator outlet. In addition, as shown in experimental studies, such as [3], [5], and [16], the control of Rankine systems for mobile applications is far from trivial.

Endo et al. [5] present a Rankine system for WHR from a spark ignition engine using water as working fluid and a volumetric expander to produce electric power. Experimental results are provided for a decentralized control system composed of two proportional controllers with feedforward.

More recently, the study [3] also presents experimental results based on a steam Rankine cycle. Here, the main originality is the use of a first-principle model for computation of a (static) feedforward on the pump speed.

Global energy management approaches for vehicles' integrating Rankine systems have also been presented, namely, in [17] (for a passenger car) and [18] (for a heavyduty vehicle), based on the Pontryagin minimum principle. More recently, [19] addresses the problem of maximizing the power produced by an ORC on board a diesel-electric rail car, first offline via dynamic programming, then online via dynamic real-time optimization. But the experimental assessment of such (high-level) approaches still requires an efficient low-level control, allowing to tightly control the working fluid state at the evaporator outlet.

On the more general topic of ORC for WHR operating with variable heat sources (not necessarily for transport applications), Hou et al. [20] and Zhang et al. [21], [22] apply control strategies based on linear models (Linear Quadratic Regulator or Model Predictive Control control), validated around one operating point. Reference [23] deals with the modeling and control of an ORC on larger operational ranges. However, the hot source variations used for simulation are much slower than those observed at the exhaust of an automotive engine, especially in terms of mass flow rate.

A somewhat richer literature exists on dynamic modeling and control of vapor-compression cycles, the reverse of Rankine cycle [24]-[26]. More particularly, in [27], a solid approach is presented for multivariable $H_{\infty}$ synthesis.

\section{Paper Contribution and Organization}

This paper addresses the control design of an ORC with a kinetic turbine. For this system, a hierarchical and modular control structure has been designed, implemented, and validated experimentally on an engine test-bed cell on a heavyduty road cycle. First, a baseline strategy for SH regulation (with the pump mass flow rate as the manipulated variable) is improved by combining a dynamic feedforward term to a commonly used gain-scheduled PID approach. The robustness of the feedforward term computation (based on model inversion) is demonstrated, allowing an embedded implementation. Compared with the preliminary version of this paper presented in [28] and [29], experimental results, representative of a long-haul truck mission, illustrate here the enhanced performance in terms of disturbance rejection.

This approach is then extended to the multivariable case, with the use of the evaporator bypass as an additional actuator, allowing the tracking of a pressure set point while maintaining the previous $\mathrm{SH}$ regulation performances. The proposed scheme combines an additional nonlinear controller with an implicit extended Kalman filter (EKF) for wall temperature estimation. An original contribution lies with the use of the exhaust bypass to recover the degree of freedom lost, because the turbine is kinetic and not of the positive-displacement type.

This paper is organized as follows. Section II describes the main components of the system (actuators and available sensors) and details the main control requirements. Section III briefly describes the reference model from which is derived a nonlinear reduced model for control purpose. The $\mathrm{SH}$ controller is then designed in Section IV and validated with experimental results. In Section V, a new multivariable control scheme based on an observer is introduced, and the results are validated in simulation. Finally, the conclusions are drawn in Section VI.

\section{SySTEM DESCRIPTION}

The system considered here is shown in Fig. 2. It is an ORC system for a heavy-duty diesel engine using a turbine for the expansion of the working fluid. A description of the main system variables follows, using the nomenclature given in Table I.

\section{A. Inputs-Outputs}

Four actuators are available, as shown in Fig. 3.

1) The pump, whose speed $N_{\text {pump }}$ allows to control the working fluid mass flow entering the evaporator. It will 
TABLE I

NOMENCLATURE

\begin{tabular}{cccc}
\hline Symbols & & & \\
$\alpha$ & Heat transfer coefficient $\left(\mathrm{W} /\left(\mathrm{m}^{2} \mathrm{~K}\right)\right)$ & Subscripts & \\
$\eta$ & efficiency $(-)$ & $d$ & desired \\
$\rho$ & Density $\left(\mathrm{kg} / \mathrm{m}^{3}\right)$ & evap & evaporator \\
$c$ & Heat capacity $(\mathrm{J} /(\mathrm{kg} \mathrm{K}))$ & exh & exhaust gas \\
$d$ & Disturbances vector & $i$ & zone i \\
$h$ & Specific enthalpy $(\mathrm{J} / \mathrm{kg})$ & inlet & working fluid \\
$L$ & Normalized zone length $(-)$ & $l$ & saturated liquid \\
$m$ & Mass $(\mathrm{kg})$ & out & outlet \\
$\dot{m}$ & Mass flow rate $(\mathrm{kg} / \mathrm{s})$ & turb & turbine \\
$N$ & Rotation speed $(\mathrm{rpm})$ & $v$ & saturated vapor \\
$p$ & Pressure $(\mathrm{Pa})$ & $w$ & wall \\
$S$ & Area $\left(\mathrm{m}^{2}\right)$ & & \\
$T$ & Temperature $(\mathrm{K})$ & Superscript & \\
$S H$ & Superheating $(\mathrm{K})$ & & Set Point \\
$V$ & Volume $\left(\mathrm{m}^{3}\right)$ & & \\
$V o$ & by-pass opening $(\%)$ & &
\end{tabular}

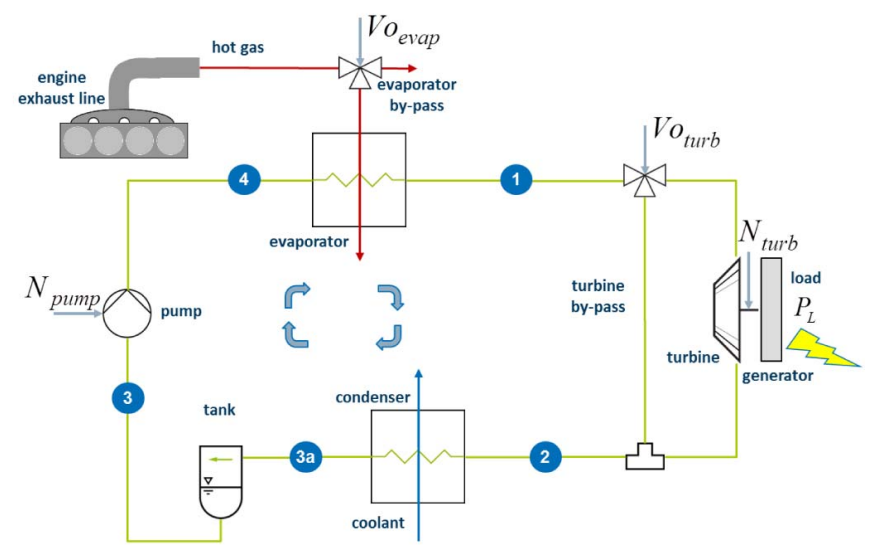

Fig. 2. Schematic of the ORC system in the experimental setup.

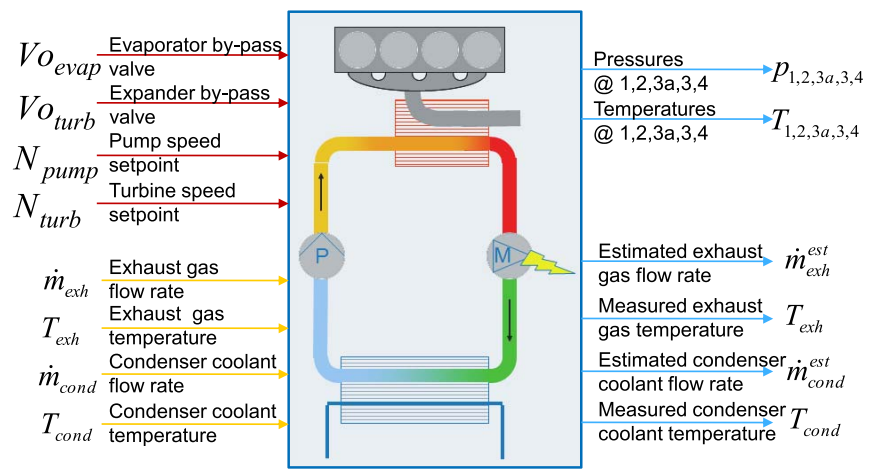

Fig. 3. ORC system inputs-outputs.

be used to control the $\mathrm{SH}$ (defined as the difference between the fluid temperature and its evaporation temperature) at evaporator outlet.

2) The evaporator bypass $V o_{\text {evap }}$ controlling the fraction of exhaust gas entering the evaporator. It will be used to control the pressure in the evaporator. The choice of such a decentralized control for $\mathrm{SH}$ and pressure control is based on two-time-scale considerations (working fluid dynamics are much faster than wall thermal dynamics). Hence, as detailed in Section V, SH will be assumed

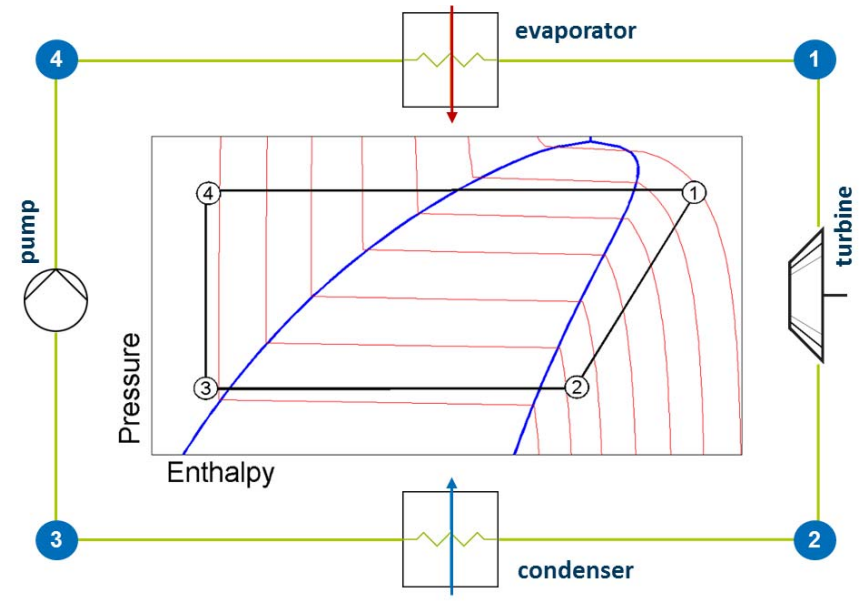

Fig. 4. Rankine cycle for a dry fluid.

perfectly regulated by pump mass flow, allowing to encompass the model complexity.

3) The turbine speed $N_{\text {turb }}$ entering the load control system. In the present case of a kinetic turbine, its influence on working fluid condition at evaporator outlet can be neglected while it provides a degree of freedom to optimize the power production. This optimization is not within the scope of this paper (the interested reader can refer to [30] and references therein).

4) The turbine bypass $V o_{\text {turb }}$ intended to protect the turbine from fluid condensation. It will be kept open as long as fluid condition at evaporator outlet is not safe for the turbine while it should be kept closed during production mode. Hence, it will be used as an ON-OFF actuator.

As shown in Fig. 3, measurements of the pressuretemperature pairs $(p, T)$ between each component are available (corresponding to the corner points $1, \ldots, 4$ of the thermodynamic cycle in Fig. 4). The available measurements can be used to estimate key output variables, such as SH, subcooling, or enthalpy, from fluid thermodynamic properties.

Respecting exhaust gas conditions, the temperature $T_{\text {exh }}$ is measured while an estimation of the mass flow $\dot{m}_{\text {exh }}$ is provided by the engine control unit. 
By contrast, no sensors are available inside the heat exchangers. In particular, the temperature of the wall is not measured.

\section{B. Control Requirements}

The main objective of the supervision and control system is to maximize the production of electric energy during vehicle usage, in the presence of variations in engine exhaust gas conditions.

This objective can be addressed by a two-level closed-loop control strategy [19], [23], where a real-time optimization provides (optimal) set points to the low-level controller, which computes the control values. This paper focuses on the evaporator outlet pressure and SH low-level controllers required by the supervisory control proposed in [19] for a diesel-electric railcar, which could also be applied to the present case study.

Even without the optimization layer (in which case the set point can be chosen constant), the proposed low-level controller remains relevant as it ensures system safety. Indeed, several output constraints must be satisfied, in particular, at the evaporator outlet, to protect the turbine from fluid condensation (requiring the $\mathrm{SH}$ to be strictly positive), and to avoid an unsafe pressure level.

\section{Modeling}

This section describes the modeling of the ORC components needed to predict the fluid state at evaporator outlet (characterized by the pressure $p$ and $\mathrm{SH}$ values) during nominal operation, that is, when superheated vapor feeds the turbine. A reduced model is then presented, for control design.

\section{A. Evaporator Model}

In systems, implementing the Rankine thermodynamic cycle, the working fluid enters the evaporator in a liquid state and exits in a superheated vapor state. A classic 1-D representation of heat exchangers (along the fluid displacement direction $z$ ) is given by mass and energy balances for the fluid and the wall [31]. The evolution of fluid and wall variablesnamely fluid mass flow $\dot{m}$, specific enthalpy $h$, pressure $p$, and wall temperature $T_{w}$-is then described by

$$
\left\{\begin{array}{l}
\frac{V_{f}}{L} \frac{\partial \rho}{\partial t}+\frac{\partial \dot{m}}{\partial z}=0 \\
\frac{V_{f}}{L} \frac{\partial(\rho h)}{\partial t}-\frac{V_{f}}{L} \frac{\partial p}{\partial t}+L \frac{\partial \dot{m}}{\partial z}=\frac{S_{f}}{L} \alpha_{f}\left(T_{w}-T_{f}\right) \\
c_{w} \rho_{w} V_{w} \frac{\partial T_{w}}{\partial t}=S_{f} \alpha_{f}\left(T_{w}-T_{f}\right)+S_{w} \alpha_{\mathrm{exh}}\left(T_{\mathrm{exh}}-T_{w}\right)
\end{array}\right.
$$

where $V_{f}, V_{w}, S_{f}$, and $S_{w}$ are (constant) design parameters. Density $\rho$ and temperature $T_{f}$ of the fluid are nonlinear maps of $p$ and $h . T_{\mathrm{exh}}$, representing the exhaust gas temperature, is considered as a time-varying input for the evaporator model. $\alpha_{\text {exh }}$ (resp. $\alpha_{f}$ ) is the heat exchange coefficient between the wall and the exhaust gas (resp. the working fluid). Notice that the above model is a system of three coupled nonlinear partial differential equations. Such a representation is difficult

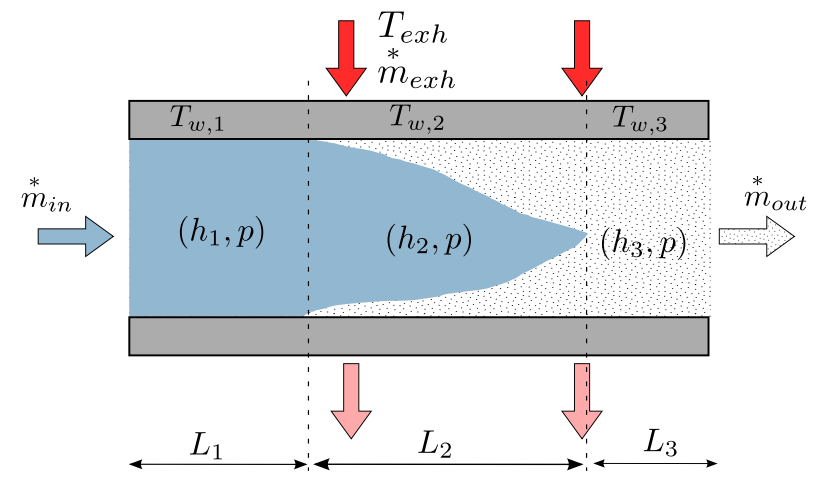

Fig. 5. MBs layout for the evaporator.

to deal with for control and estimation purposes. Therefore, a discretization of system (1) is used.

Among the methods for discretization of system (1), the use of moving boundaries (MBs) results in a relatively low order model. As shown in Fig. 5, the MB model monitors the length of each fluid phase along the evaporator: the normalized zone lengths $L_{1}, L_{2}$, and $L_{3}$ track the liquid, two phase and vapor zones, respectively. Fluid and wall dynamics are then captured by the seven state variables $\left(T_{w, 1}, T_{w, 2}\right.$, $T_{w, 3}, L_{1}, L_{2}, h_{3}$, and $p$ ). A more detailed representation of this model may be found in [31]. In the following, it is referred as the reference model that will be used for simulation purposes in Section V-D.

In an ORC (that is with a dry working fluid [32]), the fluid enters the condenser in a vapor state and exits in a liquid state or in a two-phase state depending on the cooling conditions and on the pressure imposed by the tank, acting as a separator. Applying the MB approach to the low-pressure (LP) part of the circuit generally yields a high-order hybrid model (the number of states changes depending on fluid conditions at the condenser outlet). However, as it will be justified in Section III-C, condenser modeling is not necessary for our control purposes.

\section{B. Pump and Turbine Models}

Since pump and turbine dynamics are very fast compared with exchanger dynamics, they are modeled by algebraic equations. The (positive displacement) pump produces a mass flow rate proportional to its rotational speed

$$
\dot{m}_{\text {pump }}(t)=\rho_{\text {pump }}(t) \eta_{\text {pump }} V_{\text {pump }} N_{\text {pump }}(t)
$$

where its volumetric efficiency $\eta_{\text {pump }}$ can be considered constant in nominal conditions. At the evaporator outlet, the fluid in a vapor state expands through the turbine nozzle. For nominal mass flow rate values, the fluid then reaches supersonic speeds that allows to neglect the influence of the outlet pressure [33]

$$
\dot{m}_{\text {evap,out }}(t)=C_{d} S_{\text {turb }} \sqrt{2 \rho\left(p_{\text {evap,out }}(t), \mathrm{SH}(t)\right) p_{\text {evap,out }}(t)}
$$

where $S_{\text {turb }}$ is the turbine orifice equivalent area and $C_{d}$ is the discharge coefficient. 


\section{Nonlinear Control-Oriented Model}

Designing a controller based on a full model of the Rankine cycle proves a complex and challenging problem. In the literature, model-based control generally copes with the complexity of a reference model, such as the one described earlier, by linearization around an operating point [34] or a set of operating points [35]. However, [3] and [36] underline the need of considering the nonlinear behavior of the Rankine system for control design, as its static gains and response times strongly vary with the operating conditions. Reference [37] attempts to cast the evaporator control problem for a similar system (a vapor-compression cycle for refrigeration) in a linear parameter varying framework; this approach is made very difficult by the large number of scheduling variables involved.

Here, a two-time-scale dynamic behavior is assumed where wall temperatures capture the slow dynamics. Moreover, only the high-pressure (HP) parts of the ORC will be used (which includes the pump, the evaporator, and the turbine).

Indeed, expression (3) outlines that the effect of fluid conditions at the turbine outlet can be neglected. Furthermore, the thermal inertia of the tank slows down the variations of pump inlet temperature. Such considerations allow to decouple the HP part of the cycle from the LP part (which includes the condenser and the tank). Evaporator inlet working fluid temperature $T_{f \text {,in }}$ is then considered as a (measured) disturbance for the HP part.

The model can be further reduced assuming the fluid to be at thermodynamic equilibrium. For a steam Rankine cycle, [36] shows that slow evaporator dynamics are due to wall temperatures and that a third-order model can be effectively used for disturbance rejection.

The reduced model of the evaporator is derived from the physical equations given in the following. To simplify notations, all the subscripts of variables relating to the evaporator are dropped.

1) Working Fluid Mass Balance: Assuming working fluid at a steady state leads to consider a homogeneous mass flow (denoted by $\dot{m}$ in the following) along the evaporator equal to the pump mass flow

$$
\dot{m}_{\mathrm{in}, i}(t)=\dot{m}_{\mathrm{out}, i}(t)=\dot{m}_{\mathrm{pump}}(t), \quad i=1, \ldots, 3 .
$$

2) Working Fluid Energy Balance: Energy balance equilibrium for working fluid is written for each of the three zones (indexed by $i$ )

$$
0=\dot{m}(t)\left(h_{\mathrm{in}, i}(t)-h_{\mathrm{out}, i}(t)\right)+\dot{Q}_{f, i}(t) \quad L_{i}(t)
$$

where

$$
\dot{Q}_{f, i}(t)=S_{f} \alpha_{i}\left(T_{w, i}(t)-T_{f, i}(t)\right)
$$

represents the heat transfer from wall and $S_{f}$ is the wall-fluid exchange area. $T_{f, 2}$ (the two-phase zone temperature) is the evaporation temperature that only depends on pressure. The liquid zone temperature can be computed as the average of evaporator inlet temperature and boiling temperature

$$
T_{f, 1}(p(t), t)=0.5 T_{f, \text { in }}(t)+0.5 T_{f, 2}(p(t)) .
$$

The vapor zone temperature is expressed according to the $\mathrm{SH}$ value

$$
T_{f, 3}(p(t), \mathrm{SH}(t))=T_{f, 2}(p(t))+0.5 \mathrm{SH}(t) .
$$

Notice that a (constant) coefficient $\alpha_{i}$ is chosen for each zone, reflecting significant differences in heat transfer efficiency induced by the working fluid conditions.

3) Wall Energy Balance: Wall energy balance yields the following (dynamic) equation for each zone:

$$
m_{w} c_{w} \frac{d T_{w, i}}{d t}=\dot{Q}_{\mathrm{exh}, i}(t)-\dot{Q}_{f, i}(t)
$$

where

$$
\begin{aligned}
\dot{Q}_{\mathrm{exh}, i}(t)= & \dot{m}_{\mathrm{exh}}(t) c_{\mathrm{exh}}\left[1-\exp \left(-\frac{\alpha_{\mathrm{exh}} S_{\mathrm{exh}}}{\dot{m}_{\mathrm{exh}}(t) c_{\mathrm{exh}}}\right)\right] \\
& \times\left[T_{\mathrm{exh}}(t)-T_{w, i}(t)\right]
\end{aligned}
$$

represents the heat transfer from exhaust gas and $S_{\text {exh }}$ is the wall-exhaust gas exchange area.

4) Differential Algebraic Equation System: The abovementioned equations are completed by interface equations. Fluid enthalpies and mass flows at the inlet of zones 2 and 3 correspond to those at the outlet of zones 1 and 2, that is

$$
h_{\mathrm{in}, i+1}(t)=h_{\mathrm{in}, i}(t), \quad i=1,2 .
$$

For the two-phase zone, inlet and outlet enthalpies correspond to saturation values

$$
h_{\text {in }, 2}(p(t))=h_{l}(p(t)), \quad h_{\text {out }, 2}(p(t))=h_{v}(p(t))
$$

where $h_{l}$ and $h_{v}$ are, respectively, the saturated liquid enthalpy and the saturated vapor enthalpy that, therefore, only depend on pressure. Eventually, balance and interface equations form a differential algebraic equation (DAE) system with three dynamic states $\left(T_{w, 1}, T_{w, 2}\right.$, and $\left.T_{w, 3}\right)$.

Remark 1: Notice that the above model is only relevant for nominal conditions as it does not handle the problem when one or two zones do not exist (during start-stop operations). However, the model-based controller detailed in Section IV will be completed to manage start-stop procedures. Details on this overall strategy will be given in Section IV-B.

In the case of a positive-displacement expander, the additional degree of freedom yields an explicit system, and a model inversion can be computed analytically, allowing effective tracking of pressure at evaporator outlet [36]. In Section IV, this inversion-based approach will be adapted to the case of a kinetic turbine and will be used to analyze the robustness of its computation scheme.

\section{SUPERHEATING CONTROL}

In this section, the objective is to design a controller of the SH at the evaporator outlet. Effective SH control is a key issue when controlling an ORC system, as cycle efficiency and turbine safety depend on it. As pointed out in [38], SH must be kept as low as possible to ensure good ORC efficiency when using high molecular weight organic fluids. But, SH must always remain positive to prevent the formation of droplets that could damage the turbine. 


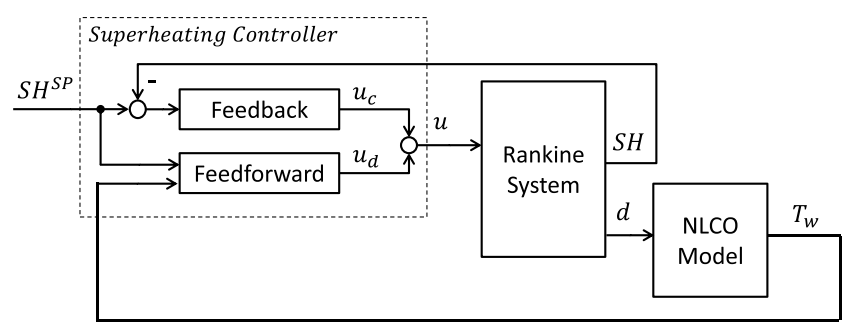

Fig. 6. Controller with inverse of the nonlinear control-oriented model in the feedforward path.
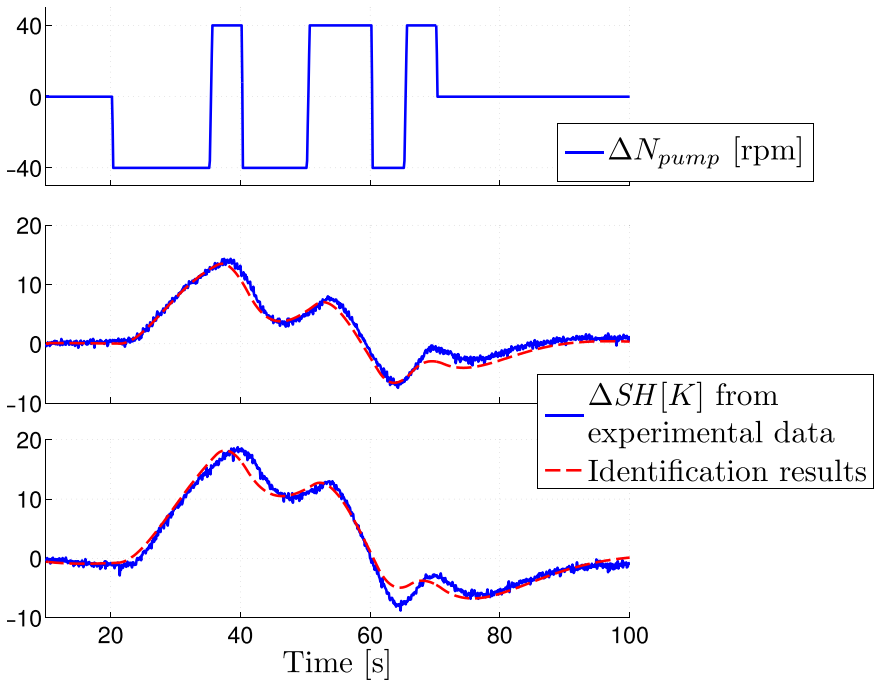

Fig. 7. $\mathrm{SH}-N_{\text {pump }}$ pair identification on two different operating points, using under damped second-order transfer functions.

In a nominal mode, when power is produced, the expander bypass is closed (for the sake of efficiency) and only one actuator is fast enough to tightly control $\mathrm{SH}$ at evaporator outlet: the pump speed $N_{\text {pump }}$ or equivalently, from relation (2), the pump mass flow rate $\dot{m}_{\text {pump }}$.

The ORC system considered has a second (slower) actuator, the exhaust bypass, which can be used to reduce the hot gas enthalpy flow rate so as to limit the pressure in the circuit. This slower control loop, detailed in Section V, acts as a disturbance to the faster SH control loop.

\section{A. Nonlinear Inversion-Based Control}

The SH control scheme is described in Fig. 6. The focus is on improving the baseline control strategy using a model-based approach. The improvements come from an extensive system identification campaign, which allows model-based tuning of PID controllers and, more particularly, from a dynamic feedforward term computed from a nonlinear reduced model of the HP part of the system.

1) Feedback Controller: Input-output dynamics are identified at different operating points via a set of linear models. The good fitting obtained with damped second-order transfer functions (see Fig. 7) justifies the use of a gain-scheduled PID controller (and not just a PI) in the feedback path. PID controllers are tuned with the well-known internal model control (IMC) method (more details on IMC method can be found in [39]). Following the gain scheduling idea presented in [27] in the context of an air conditioning system, the feedback control value is finally obtained by a linear interpolation of these local controllers, using the pressure value as a scheduling variable.

2) Inverse Reduced Model: The evaporator model derived in Section III-C is merged with the nozzle mass flow equation (3) and inverted to be used in the feedforward path for disturbance rejection. Evaporator mass flow computed from this reduced model then constitutes the feedforward part $u_{d}$ of the control input (see Fig. 6), as detailed thereafter. ${ }^{1}$

Notice that, among the disturbances appearing in the model and which can be gathered into the vector $d=$ [ $\left.T_{\text {exh }} \dot{m}_{\text {exh }} T_{f, \text { in }}\right]^{T}, T_{\text {exh }}$ and $T_{f \text {,in }}$ are measured, while an estimation of $\dot{m}_{\text {exh }}$ is provided by the engine control unit.

Providing that pressure $p$ is known, the dynamic part of the resulting system is described by the following (explicit) system:

$\left\{\begin{array}{l}\frac{d T_{w, 1}}{d t}=-\beta_{1}\left(T_{w, 1}-T_{f, 1}(p, d)\right)-\eta_{\mathrm{exh}}\left(T_{w, 1}-T_{\mathrm{exh}}\right) \\ \frac{d T_{w, 2}}{d t}=-\beta_{2}\left(T_{w, 2}-T_{f, 2}(p)\right)-\eta_{\mathrm{exh}}\left(T_{w, 2}-T_{\mathrm{exh}}\right) \\ \frac{d T_{w, 3}}{d t}=-\beta_{3}\left(T_{w, 3}-T_{f, 3}(p, \mathrm{SH})\right)-\eta_{\mathrm{exh}}\left(T_{w, 3}-T_{\mathrm{exh}}\right)\end{array}\right.$

where

$$
\begin{aligned}
\beta_{i} & =\frac{S_{f} \alpha_{i}}{m_{w} c_{w}}, \quad i=1, \ldots, 3 \\
\eta_{\mathrm{exh}} & =\frac{\dot{m}_{\mathrm{exh}} c_{\mathrm{exh}}}{m_{w} c_{w}}\left[1-\exp \left(-\frac{\alpha_{\mathrm{exh}} S_{\mathrm{exh}}}{\dot{m}_{\mathrm{exh}} c_{\mathrm{exh}}}\right)\right]
\end{aligned}
$$

while $p$ can be computed from the (implicit) algebraic part

$$
\left\{\begin{array}{l}
\dot{m}=C_{d} S_{\text {turb }} \sqrt{2 \rho(p, \mathrm{SH}) p} \\
L_{1}=\dot{m} \frac{\left.h_{l}(p)-h_{\mathrm{in}}(d)\right)}{S_{f} \alpha_{1}\left(T_{w, 1}-T_{f, 1}(p, t)\right)} \\
L_{2}=\dot{m} \frac{h_{v}(p)-h_{l}(p)}{S_{f} \alpha_{2}\left(T_{w, 2}-T_{f, 2}(p)\right)} \\
L_{3}=\dot{m} \frac{h_{\mathrm{out}}(p, \mathrm{SH})-h_{v}(p)}{S_{f} \alpha_{3}\left(T_{w, 3}-T_{f, 3}(p, \mathrm{SH})\right)} \\
L_{1}+L_{2}+L_{3}=1 .
\end{array}\right.
$$

In order to ensure that a robust implementation of the controller is possible, the implicit system (7) needs to be analyzed. This is done in Proposition 1 that applies for the physical domain defined in Assumption 1. For the sake of simplicity, $\mathrm{SH}^{\mathrm{SP}}$ will be assumed constant and equal to $30 \mathrm{~K}$ in the following, but the results remain valid for any other strictly positive values of the $\mathrm{SH}$.

Assumption 1: The following physical constraints are fulfilled:

$$
\begin{aligned}
p & <p^{\max } \\
T_{f, \text { in }}^{\min } & <T_{f, \text { in }}<T_{f, \text { in }}^{\max } \\
T_{f, i} & <T_{w, i}, \quad i=1,2,3
\end{aligned}
$$

\footnotetext{
${ }^{1}$ In the following, the implicit time dependencies are dropped for compactness.
} 
where $p^{\max }, T_{f, \text { in }}^{\min }$, and $T_{f, \text { in }}^{\max }$ are positive constants, characterizing the nominal conditions for the working fluid. ${ }^{2}$

Remark 2: The physical constraints (8a) and (8b) imposed by Assumption 1 are satisfied for the considered system and working fluid in normal conditions (larger pressures or inlet temperatures do not match safety conditions and/or efficiency considerations and would lead to system shutdown by the control system supervisor).

On the other hand, the physical constraint (8c) means that the fluid is heated by the wall. This might not be verified during start-stop operations. However, under nominal conditions (for which the control law is designed), none of these conditions is restrictive.

Proposition 1: Consider the algebraic system (7) applied to the working fluid R245fa, and assume that Assumption 1 holds for the following operation conditions:

$$
p^{\max }=25 \mathrm{bar}, \quad T_{f, \text { in }}^{\min }=10^{\circ} \mathrm{C}, \quad T_{f, \text { in }}^{\max }=40^{\circ} \mathrm{C} .
$$

Then, the residual function $\varphi$ defined by

$$
\varphi=1-L_{1}-L_{2}-L_{3}
$$

is strictly decreasing with respect to $p$, i.e., $(\partial \varphi / \partial p)<0$.

The proof of Proposition 1 is postponed to the Appendix.

Finally, since $\varphi$ decreases monotonically with $p$, one can numerically solve (7), e.g., by a bisection method, ensuring a robust (inline) implementation of the controller. In other words, given a disturbance vector $d$ and a state vector $T_{w}$ computed by the integration of the (stable) equation system (6), one can compute the corresponding pressure value $p$. The feedforward part $u_{d}$ is then deduced from the nozzle mass flow equation

$$
u_{d}=C_{d} S_{\mathrm{turb}} \sqrt{2 \rho(p, \mathrm{SH}) p} .
$$

Eventually, the pump mass flow $u_{d}$ is transposed into a pump speed control signal assuming the linear relation (2).

\section{B. Experimental Results}

In this section, experimental results demonstrate that the dynamic feedforward allows significant gains in performance when coupled to the commonly used PID approach for SH regulation. Experimental validation was performed by means of the Rankine system plugged on a heavy-duty diesel engine shown in Fig. 8.

1) SH Regulation Performance: In Fig. 9, we compared the two control strategies (with or without feedforward), for the same variations of exhaust gas conditions. These transient profiles [Fig. 9(a)] have been obtained by varying engine torque and speed in order to compare the two strategies on a large panel of operating conditions.

The feedforward action demonstrates significant performance improvements [Fig. 9(c)]. Indeed, the maximum error $\left(\mathrm{SH}-\mathrm{SH}^{\mathrm{SP}} \mid\right)$ is only about $1.9 \mathrm{~K}$ in this case compared with about $10 \mathrm{~K}$ without feedforward. Notice that this would allow to reduce considerably the SH set point, thus increasing cycle efficiency, while keeping the same safety margins during power production [38].

\footnotetext{
${ }^{2}$ The numerical values considered for this application (namely for the organic fluid R245fa) are specified in Proposition 1.
}

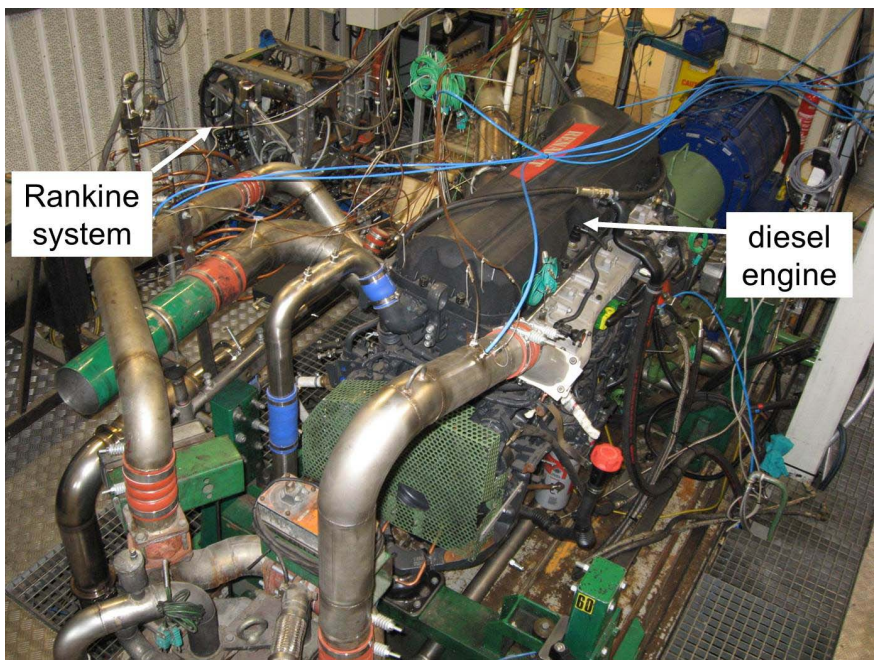

Fig. 8. Picture of the Rankine system plugged on a heavy-duty diesel engine.

2) SH Regulation on a Representative Heavy-Duty Road Cycle: The SH controller detailed in Section IV-A (designed for nominal conditions) must be complemented to manage start-stop procedures. The considered supervision structure for the Rankine pilot process is similar to that described in [40]. For the sake of completeness, safety and management modes used during the experiment are detailed in the following.

1) Stop: This mode is maintained as long as the exhaust gas is not hot enough. Evaporator bypasses the evaporator and pump speed is brought to zero.

2) Cold Idle: Exhaust gas enters the evaporator while pump circulates fluid at a constant mass flow (open loop).

3) Hot Idle: This mode is enabled when superheated vapor appears at the evaporator outlet $(\mathrm{SH}>0)$. The $\mathrm{SH}$ control scheme described in Fig. 6 is then used (closed loop).

4) Nominal Mode: This mode is enabled when $\mathrm{SH}$ is steady and large enough to ensure turbine safety. Power production is then possible.

This control strategy is finally validated on a realistic exhaust conditions profile, corresponding to a heavy-duty road cycle (Fig. 10). SH is tightly controlled along the entire duration of the cycle (lasting over $50 \mathrm{~min}$ ), demonstrating the robustness of the proposed controller. Moreover, thanks to an early stabilization of the $\mathrm{SH}$, the nominal mode is enabled during most of the experiment, thus creating the conditions for continuous power production [Fig. 10(c)].

Notice that to ensure a safe pressure level in the circuit, the evaporator bypass was used to limit the hot gas enthalpy flow rate [Fig. 10(a)].

This heuristic use of the bypass, which does not consider the system dynamics, presents two main drawbacks. First, the hot gas flow may be restricted abruptly in response to increases in engine load. Second, it does not allow the tracking of a varying pressure set point, which may be required by an overall Rankine system supervisor (for instance, in the presence of limited cooling capacities, see [19]).

This trajectory-tracking problem is addressed in Section V. 

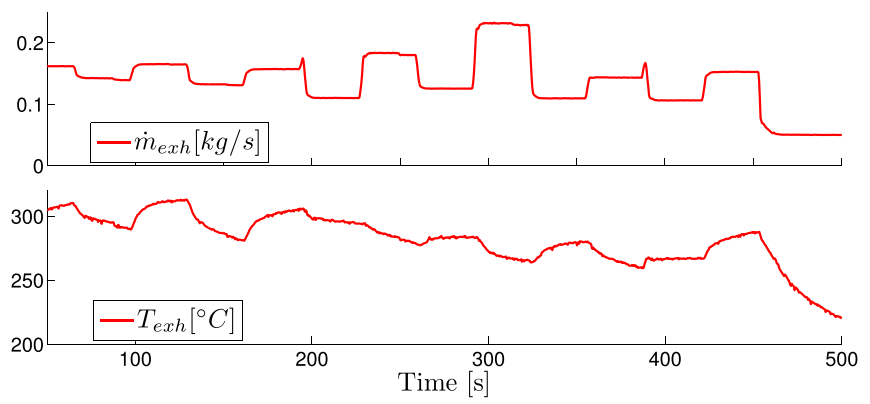

(a)
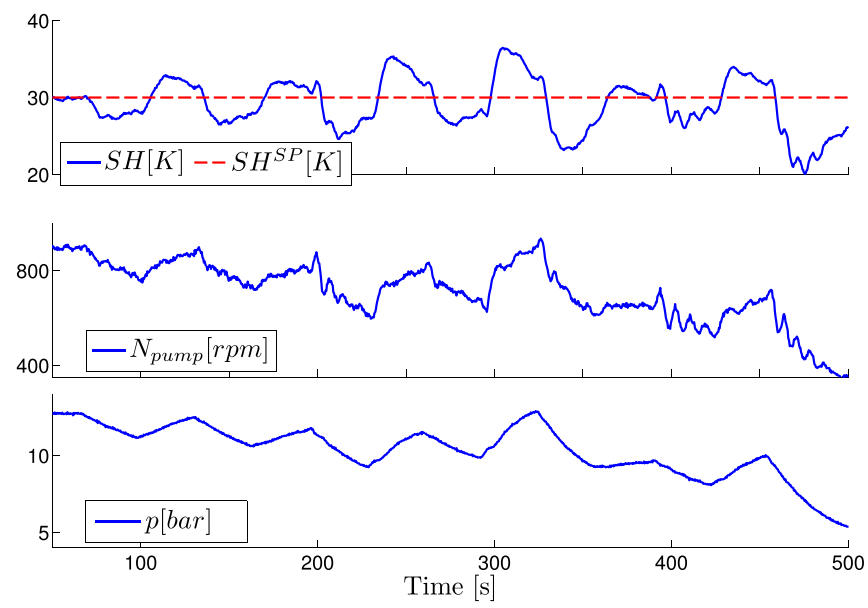

(b)
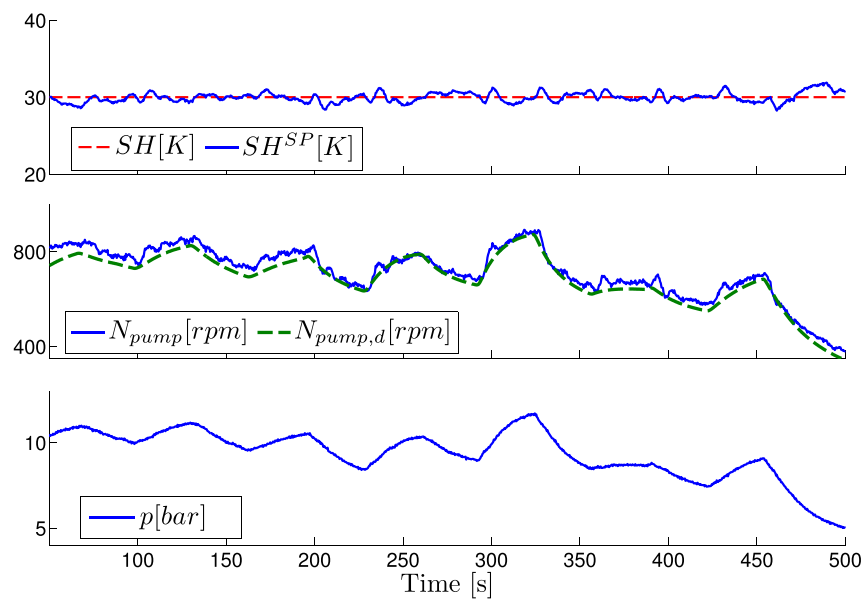

(c)

Fig. 9. Experimental result. Dynamic inverse model improve SH control. (a) Disturbances (exhaust gas conditions). (b) Control performance: PID (alone). (c) Control performance: PID with dynamic inverse model in feedforward path.

\section{Pressure Control}

\section{A. Problem Formulation}

In Section IV, it was experimentally shown that a nonlinear model-based monovariable control approach is more efficient than the commonly used PID approach for SH regulation. In this section, this approach is extended to the multivariable case, with the use of the evaporator bypass as a second actuator, which also allows the tracking of a pressure set point while ensuring a safe level for SH. Interestingly, despite the importance of this bypass, which is mandatory for

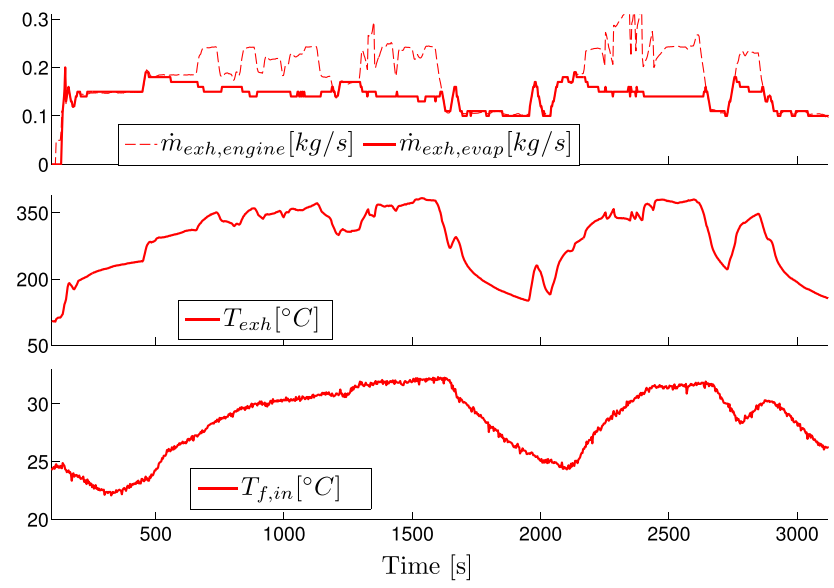

(a)
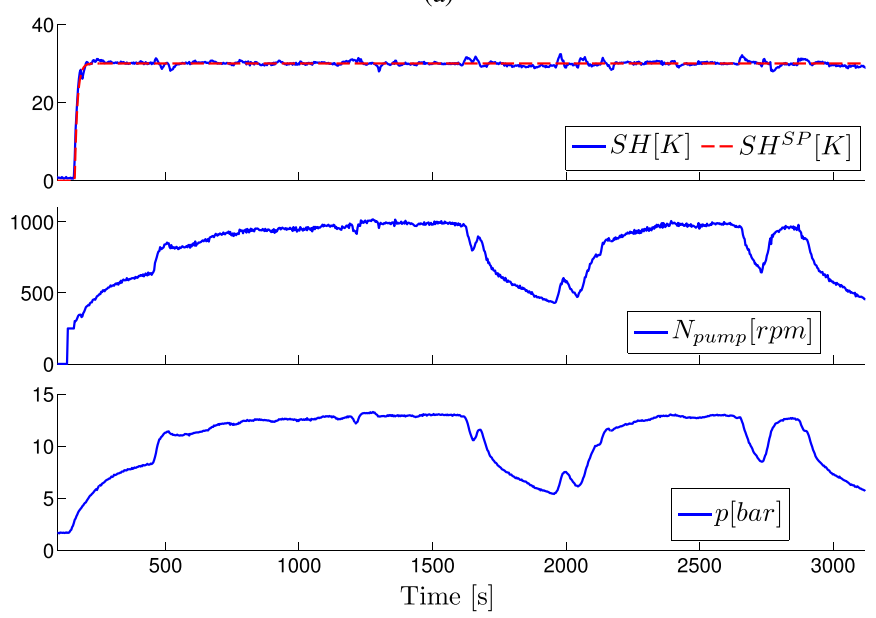

(b)

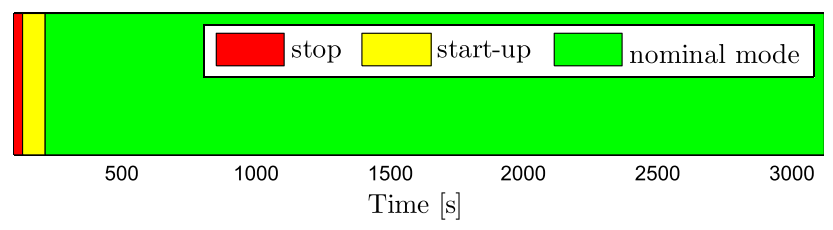

(c)

Fig. 10. Experimental result. Validation on a realistic profile of exhaust gas conditions. (a) Measured disturbances for the $\mathrm{SH}$ control. Working fluid temperature $T_{f \text {,in }}$ at evaporator inlet and exhaust gas conditions (temperature $T_{\text {exh }}$ and mass flow $\dot{m}_{\text {exh evap }}$ entering the evaporator). (b) $\mathrm{SH}$ is tightly controlled (using the pump speed $N_{\text {pump}}$ ) while a safe pressure level is ensured. (c) Automatic startup system achieves nominal operating conditions in about $1 \mathrm{~min}$.

safety reasons, only heuristic control approaches have been reported [3], [33].

Now, let us consider that the output of the system is $y=\left[\begin{array}{ll}y_{1} & y_{2}\end{array}\right]^{T}=[\mathrm{SH} p]^{T}$ (corresponding to the working fluid state at evaporator outlet) and the dynamic state is $T_{w}=\left[\begin{array}{lll}T_{w, 1} & T_{w, 2} & T_{w, 3}\end{array}\right]^{T}$ in accordance with the reduced model derived in Section III-C. In what follows, the fraction of exhaust gas entering the evaporator is assumed to be proportional to the valve position $V o_{\text {evap }}$. Consequently, the chosen control vector is $u=\left[\begin{array}{ll}u_{1} & u_{2}\end{array}\right]^{T}=\left[\begin{array}{ll}\dot{m} & \eta_{\mathrm{exh}}\end{array}\right]^{T}$ where the new second manipulated variable is

$$
\eta_{\mathrm{exh}}=V o_{\mathrm{evap}} \frac{\dot{m}_{\mathrm{exh}} c_{\mathrm{exh}}}{m_{w} c_{w}}\left[1-\exp \left(-\frac{\alpha_{\mathrm{exh}} S_{\mathrm{exh}}}{\operatorname{Vo}_{\mathrm{evap}} \dot{m}_{\mathrm{exh}} c_{\mathrm{exh}}}\right)\right] .
$$




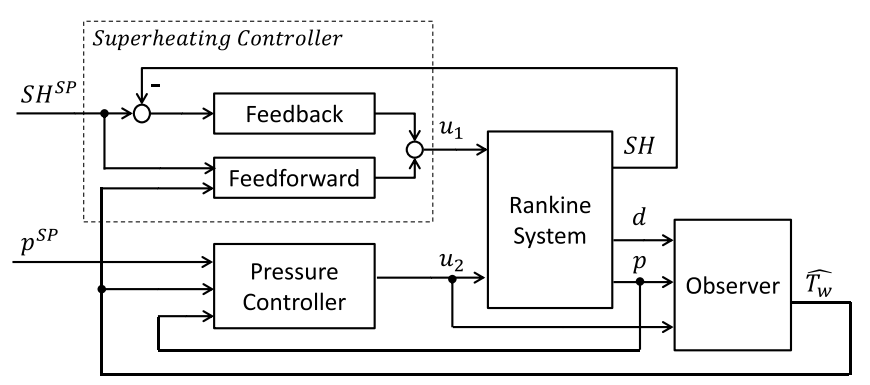

Fig. 11. Proposed closed-loop structure for control of SH and $p$. Observer feeds state estimation to model-based controller.

Rather than choosing the valve position as a control variable, the selection of $\eta_{\text {exh }}$ allows to obtain a system affine in the control as it is shown in the following.

This two-input two-output control problem is treated in two steps, assuming a two-time-scale dynamic behavior. First, the control design proposed in Section IV-A is used to regulate the SH $y_{1}$ with pump mass flow $u_{1}$. Indeed, experimental results in Section IV-B have shown that a control based on a gainscheduled PID with a dynamic feedforward allows a tight SH regulation even in the presence of fast transient conditions on exhaust gas. Then, a second nonlinear controller for the pressure $y_{2}$ will be designed that assumes that the (fast) $\mathrm{SH}$ dynamics are perfectly regulated.

As it can be noticed, the proposed control requires the knowledge of all system states (i.e., $T_{w_{i}}$ measurements). To overcome this problem, in Section IV, an open-loop model was used for the estimation of needed states. In the following, instead of the open-loop model, an observer is proposed for the state vector estimation, which will improve the robustness of the closed loop against model uncertainties. The control scheme described in Fig. 6 is taken up and completed, as shown in Fig. 11.

Assuming that the pump mass flow is fixed by the value of SH, system (6) and (7) can be rewritten in the following implicit form:

$$
\left\{\begin{array}{l}
\frac{d T_{w}}{d t}=f\left(T_{w}, p, d\right)+u_{2} g\left(T_{w}, d\right) \\
\varphi\left(T_{w}, p, d\right)=0 \\
y=p
\end{array}\right.
$$

where

$$
\begin{aligned}
& f\left(T_{w}, p, d\right)=\left(\begin{array}{c}
\beta_{1}\left(T_{f, 1}(p, d)-T_{w, 1}\right) \\
\beta_{2}\left(T_{f, 2}(p)-T_{w, 2}\right) \\
\beta_{3}\left(T_{f, 3}(p)-T_{w, 3}\right)
\end{array}\right) \\
& g\left(T_{w}, t\right)=\left(\begin{array}{c}
T_{\mathrm{exh}}-T_{w, 1} \\
T_{\mathrm{exh}}-T_{w, 2} \\
T_{\mathrm{exh}}-T_{w, 3}
\end{array}\right)
\end{aligned}
$$

with

$$
\beta_{i}=\frac{S_{f} \alpha_{i}}{m_{w} c_{w}}, \quad i=1, \ldots, 3
$$

and

$$
\varphi\left(T_{w}, p, d\right)=1-\left(L_{1}+L_{2}+L_{3}\right)
$$

with

$$
\begin{aligned}
L_{1} & =u_{1} \frac{h_{l}(p)-h_{\mathrm{in}}(d)}{S_{f} \alpha_{1}\left(T_{w, 1}-T_{f, 1}(p, d)\right)} \\
L_{2} & =u_{1} \frac{h_{v}(p)-h_{l}(p)}{S_{f} \alpha_{2}\left(T_{w, 2}-T_{f, 2}(p)\right)} \\
L_{3} & =u_{1} \frac{h_{\mathrm{out}}(p)-h_{v}(p)}{S_{f} \alpha_{3}\left(T_{w, 3}-T_{f, 3}(p)\right)} .
\end{aligned}
$$

In what follows, the main focus will be on the design of the above-mentioned observer and pressure controller, based on system (9).

\section{B. Control Design}

From Proposition 1, $(\partial \varphi / \partial p)<0$ for all $\left(T_{w}, p, d\right)$ in the physical domain defined by Assumption 1. Hence, $(\partial \varphi / \partial p)^{-1}$ is well defined on this domain, and the implicit model given by system (9) can be transformed [41] into an ordinary differential equation system

$$
\left\{\begin{aligned}
\frac{d T_{w}}{d t}= & f\left(T_{w}, p, d\right)+u_{2} g\left(T_{w}, d\right) \\
\frac{d p}{d t}= & -\left(\frac{\partial \varphi}{\partial p}\left(T_{w}, p, d\right)\right)^{-1} \frac{\partial \varphi}{\partial T_{w}}\left(T_{w}, p, d\right) \\
& \times\left[f\left(T_{w}, p, d\right)+u_{2} g\left(T_{w}, d\right)\right] \\
y=p &
\end{aligned}\right.
$$

where

$$
\begin{aligned}
\frac{\partial \varphi}{\partial T_{w}}\left(T_{w}, p, d\right)= & S_{\text {turb }} C_{d} \sqrt{\rho(p) p} \\
& \times\left(\begin{array}{c}
\frac{h_{l}(p)-h_{\text {in }}(d)}{S_{f} \alpha_{1}\left(T_{w, 1}-T_{f, 1}(p, d)\right)^{2}} \\
\frac{h_{v}(p)-h_{l}(p)}{S_{f} \alpha_{2}\left(T_{w, 2}-T_{f, 2}(p)\right)^{2}} \\
\frac{h_{\text {out }}(p)-h_{v}(p)}{S_{f} \alpha_{3}\left(T_{w, 3}-T_{f, 3}(p)\right)^{2}}
\end{array}\right) .
\end{aligned}
$$

Notice that the above system is affine in the control $u_{2}$. The feedback controller introduced in Proposition 2 takes advantage of this structure.

Proposition 2: Let $k$ be a positive real number, then the control $^{3}$

$$
u_{2}=\frac{-\varphi_{T_{w}}^{T} f\left(T_{w}, p, d\right)+k\left(p^{\mathrm{SP}}-p\right)}{\varphi_{T_{w}}^{T} g\left(T_{w}, d\right)}
$$

asymptotically stabilizes $p$ to the set point $p^{\mathrm{SP}}$ for all $\left(T_{w}, p, d\right)$ in the physical domain defined by Assumption 1. Moreover, the input $u_{2}$ and the states of system (9) remain bounded.

In order to prove Proposition 2, Lemma 2 is needed.

Lemma 1: For every $T_{f, i}(i=1, \ldots, 3), T_{\text {exh }}$ bounded and for the input $u_{2}$, which takes values in some bounded set $\mathbb{U} \subset \mathbb{R}^{+}$, the solution $T_{w}$ of system

$$
\frac{d T_{w}}{d t}=f\left(T_{w}, p, d\right)+u_{2} g\left(T_{w}, d\right) \quad \forall T_{w i}\left(t_{0}\right) \in \mathbb{R}_{+}
$$

\footnotetext{
${ }^{3}$ To simplify the presentation, the following notations are used : $\varphi_{p}=$ $(\partial \varphi / p)\left(T_{w}, p, d\right)$ and $\varphi_{T_{w}}=\left(\partial \varphi / T_{w}\right)\left(T_{w}, p, d\right)$.
} 
is uniformly bounded with respect to $t$ in $\mathbb{R}_{+}$, i.e., system (11) is bounded-input bounded-output (BIBO) stable.

In the following, we first start with the proof of Lemma 1; then the proof of Proposition 2 will be given.

Proof (Lemma 1): Considering the positive definite quadratic function $V\left(T_{w i}\right)=T_{w i}^{2} / 2$, the derivative of $V$ along the trajectories of the dynamical system (14) is given by

$$
\begin{aligned}
\frac{d V}{d t} & =T_{w, i}\left(\beta_{i}\left(T_{f, i}-T_{w, i}\right)+u_{2}\left(T_{\mathrm{exh}}-T_{w, i}\right)\right) \\
& =-T_{w, i}^{2}\left(\beta_{i}+u_{2}\right)+T_{w, i}\left(\beta_{i} T_{f, i}+u_{2} T_{\mathrm{exh}}\right) \\
& \leq-2 a V+b \sqrt{2 V} \\
& \leq-\sqrt{V}(2 a \sqrt{V}-b \sqrt{2})
\end{aligned}
$$

where $a=\inf \left(\beta_{i}+u_{2}\right)$ and $b=\sup \left(\beta_{i} T_{f, i}+u_{2} T_{\text {exh }}\right)$. Notice that $a$ and $b$ are strictly positive and bounded. From (15), it can be deduced that $(d V / d t)$ is strictly negative for $T_{w}$, such that $\left\{\left|T_{w, i}\right|>b / a, i=1, \ldots, 3\right\}$. Hence, solutions starting from the set $\left\{V\left(T_{w, i}\right) \leq(b / a)^{2} / 2\right\}$ at an initial time $t_{0}$ remain there for $t>t_{0}$, and system (11) is BIBO stable.

Proof (Proposition 2): Let $u_{2}$ be defined as in (13). Since Assumption 1 holds, $u_{2}$ is bounded. Then, the second equation of system (11) becomes

$$
\frac{d p}{d t}=-k \varphi_{p}^{-1}\left(p^{\mathrm{SP}}-p\right)
$$

Moreover, from Proposition 1, it is deduced that $\varphi_{p}<0$. So, obviously, pressure dynamics in (16) are asymptotically attracted by $p^{\mathrm{SP}}$.

Notice that the proof of the asymptotic stability assumes that the model is perfect. In practice, parameter $k$ in the control design (13) will be chosen sufficiently large to deal with model uncertainties.

\section{Observer Design}

The problem of wall temperature estimation was addressed by Luong [42], where he proposed to apply an EKF on the MB reference model described in Section III-A. Unfortunately, the limits of computational resources, particularly, stringent in an embedded context, prevent the use of such a complex model. Therefore, in what follows, an observer based on the reduced model is designed.

Let us consider the class of implicit system of the following form, which includes system (9):

$$
\left\{\begin{array}{l}
\dot{x}=F(x, z, u) \\
\Phi(x, z)=0 \\
y=h(x, z)
\end{array}\right.
$$

where $y \in \mathbb{R}^{p}, u \in \mathbb{U} \subset \mathbb{R}^{m},(x, z) \in \mathbb{R}^{n} \times \mathbb{R}^{d}, F, h$, and $\Phi=\left(\Phi_{1}, \ldots, \Phi_{d}\right)^{T}$ are assumed to be sufficiently smooth with respect to their arguments, and

$$
\frac{\partial \Phi}{\partial z}(x, z) \text { is of full rank } \forall(x, z) \in \mathcal{M}
$$

where $\mathcal{M}$ is the set of zeros of $\Phi$

$$
\mathcal{M}=\left\{(x, z) \in \mathbb{R}^{n} \times \mathbb{R}^{d} \text {, s.t. } \Phi(x, z)=0\right\} .
$$

For the implicit system of index 1 (17), Nikoukhah [43] has designed an implicit observer described by a dynamic system coupled with an optimization problem permitting to solve the algebraic constraint at each time instant.

Definition 1: An implicit observer for system (17), which converges for every input $u \in \mathbb{U}$, is a dynamical system of the form

$$
\left\{\begin{array}{l}
\frac{d \hat{x}}{d t}=\widehat{F}(\hat{x}, \hat{z}, l, y, u) \\
\frac{d l}{d t}=L(l, u), \quad l \in O \text { is an open subset of } \mathbb{R}^{k} \\
\Phi(\hat{x}, \hat{z})=0
\end{array}\right.
$$

such that for every $u \in \mathbb{U}$, the following holds.

1) $\forall l(0) \in O$, the trajectory $(l(t))_{t \geq 0}$ lies into a compact subset of $O$.

2) $\left.\forall r>0 ; \forall(x(0), z(0)) \in \mathcal{M} ; \exists r^{\prime}>0 ; \forall(\hat{x}(0), \hat{z}(0))\right) \in$ $\mathcal{M},\|(\hat{x}(0)-x(0), \hat{z}(0)-z(0))\|<r^{\prime}$ implies $\|(\hat{x}(t)-$ $x(t), \hat{z}(t)-z(t)) \|<r$, for all $t \geq 0$.

3) $\forall(x(0), z(0)) \in \mathcal{M} ; \quad \forall(\hat{x}(0), \hat{z}(0))) \in \mathcal{M}$, $\lim _{t \rightarrow+\infty}\|(\hat{x}(t)-x(t), \hat{z}(t)-z(t))\|=0$.

Here, conditions 1) and 2) ensure the stability of the observer, and condition 3) guarantees its convergence.

Based on this definition and using the notations $z=p$ and $x=T_{w}$ with $\left(T_{w}, p\right) \in \mathbb{R}^{3} \times \mathbb{R}$ and $y=p$, the gain $l(t)$ is given by a Riccati equation, and an implicit EKF for system (9) is given by [43]-[45]

$$
\left\{\begin{array}{l}
\frac{d \hat{T}_{w}}{d t}=f\left(\hat{T}_{w}, \hat{p}\right)+u_{2} g\left(\hat{T}_{w}, \hat{p}\right)-S C^{T} R^{-1}(\hat{p}-p) \\
\varphi\left(\hat{T}_{w}, \hat{p}\right)=0 \\
\frac{d S}{d t}=A S+S A^{T}-S C^{T} R^{-1} C^{T} S+Q \\
S(0)=S(0)^{T}>0
\end{array}\right.
$$

where $Q$ is a constant symmetric positive definite matrix, $R$ is a real positive constant, and

$$
A=\left.\frac{\partial\left(f+u_{2} g\right)}{\partial T_{w}}\right|_{\left(\hat{T}_{w}, \hat{p}, d\right)}, \quad C=\varphi_{p}^{-1} \varphi_{T_{w}}^{T} .
$$

\section{Simulation Results}

To demonstrate the effectiveness of the control structure described in Fig. 11, this section presents a set of simulation results ${ }^{4}$ with realistic operating conditions. After the observer validation, the controller is tested on the seven-state DAE reference model described in Sections III-A and III-B, showing remarkable robustness in the presence of model uncertainties.

1) Observer Validation: Observer (21) performance in the presence of measurement noise is shown in Fig. 12. System simulation is conducted under transient conditions. Observer (21) is initialized with initial conditions different from the reference model. The states of the observer are found to converge faster to their target values than the states of the open-loop model, if they both start with the same initial conditions. Moreover, the observer provides an efficient

\footnotetext{
${ }^{4}$ Notice that the experimental setup was not available when this part of the study was conducted.
} 


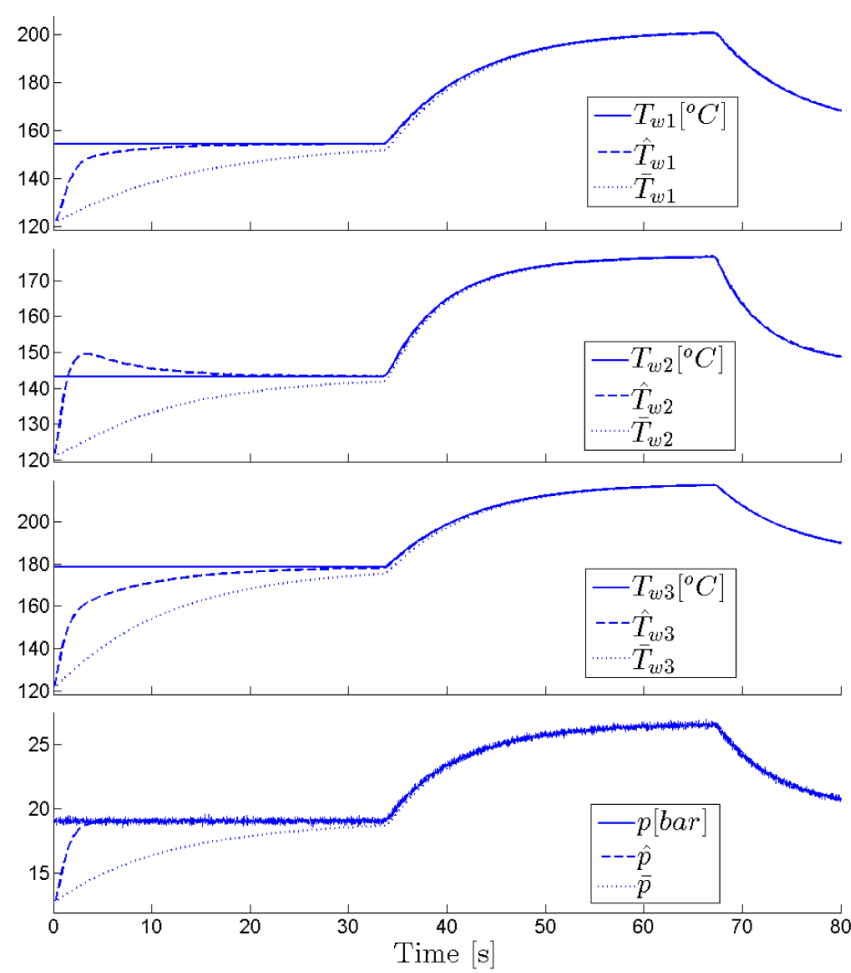

Fig. 12. Simulation results under varying inlets. Reference model (solid lines), observer (dashed lines), and reference model with observer initial conditions (dotted lines).

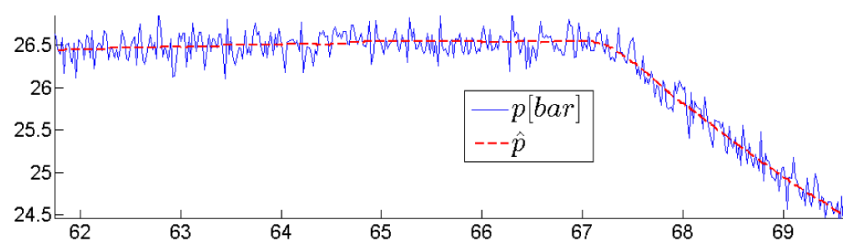

Fig. 13. Zoomed-in pressure plot of Fig. 12.

filtering of pressure measurement (Fig. 13) that will be useful to the control feedback.

2) Closed-Loop Control Assessment: Experimental data of exhaust gas conditions collected from the heavy-duty road cycle [Fig. 10(a)] were used to evaluate the closed-loop performances under realistic conditions. Moreover, in order to assess the robustness of the control, errors were introduced on two main model parameters: an error of $10 \%$ on the heat exchange coefficient between exhaust gas and evaporator wall, and of $20 \%$ on the wall volume.

Fig. 14 presents estimation results. The unmeasurable states of the reference model and their estimations are compared. Due to the model parameters errors, estimations do not converge exactly to their target values. But they still provide representative values, especially during fast transient periods.

Figs. 15 and 16 validate control capability to regulate the process output $\mathrm{SH}$ to its set point $\mathrm{SH}^{\mathrm{SP}}$, despite fast transients on exhaust conditions and dramatic variations of pressure. A tight pressure set-point tracking is also demonstrated as long as exhaust gas heat flow is sufficient. Indeed, in the time interval between 1400 and $1800 \mathrm{~s}$, pressure set point—or

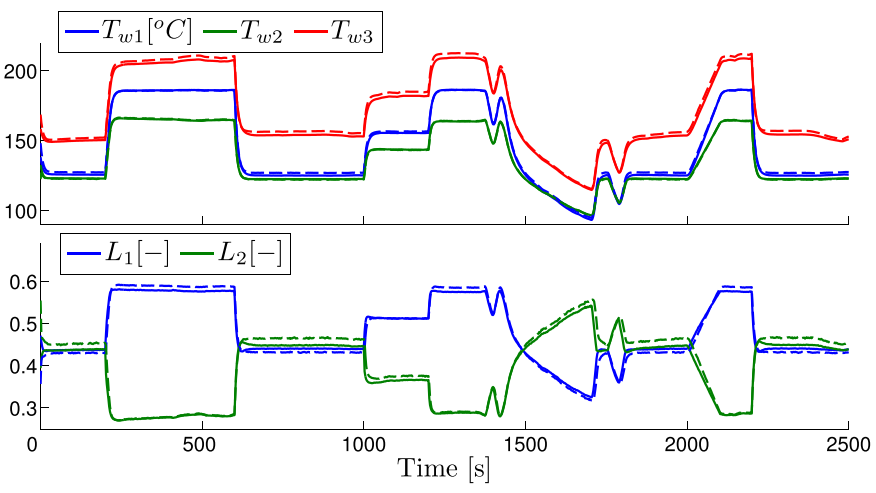

Fig. 14. Estimation (dashed lines) of reference model unmeasurable states (solid lines).

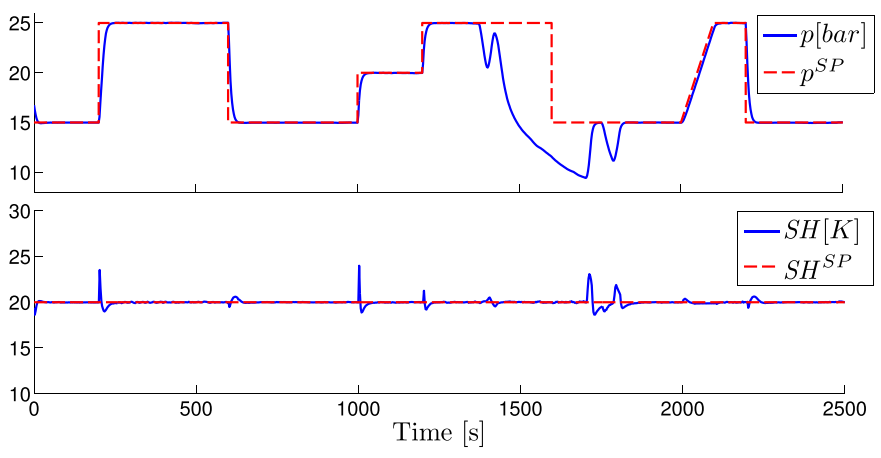

Fig. 15. Pressure set point $p^{\mathrm{SP}}$ tracking and $\mathrm{SH}$ regulation around $\mathrm{SH}^{\mathrm{SP}}$.

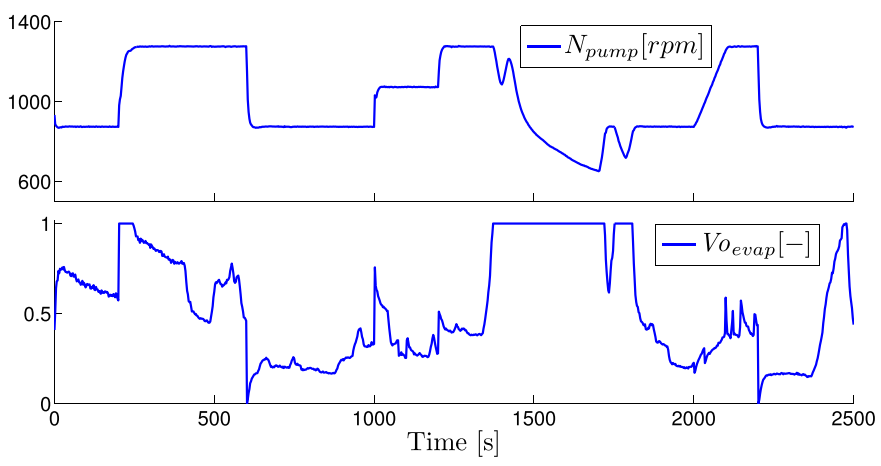

Fig. 16. Evolution of the two controlled actuators. The pump speed $N_{\text {pump }}$ and the evaporator bypass $V o_{\text {evap }}$ (when $V o_{\text {evap }}=1$, all the exhaust gas enters the evaporator).

equivalently, power production demand-cannot be satisfied due to insufficient exhaust gas heat flow.

Notice that, in this simulation, an arbitrary pressure setpoint trajectory was used to illustrate the tracking capability of the low-level control, without attempting any direct WHR optimization. However, the proposed scheme opens up the possibility to implement a two-level closed-loop control strategy [19], [23], where an energy management system would provide optimal set points to the above-described low-level controllers. Indeed, in the context of transport applications, due to limited cooling capacities [4], [10], it cannot be assumed that the optimal strategy is to minimize the exhaust bypass.

Finally, to emphasize the benefits of the observer, a second simulation is conducted where state estimation is performed via an open-loop model. Fig. 17 compares the resulting 


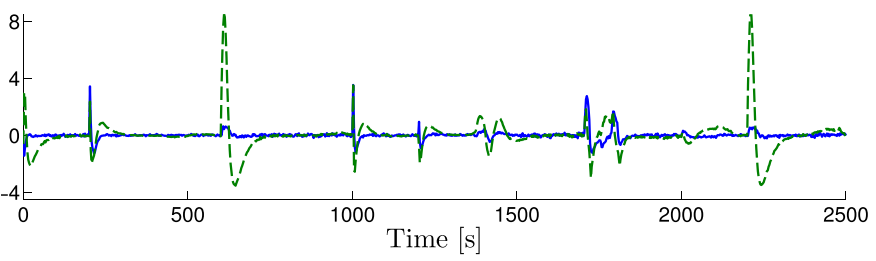

Fig. 17. SH regulation error $\left(\mathrm{SH}-\mathrm{SH}^{\mathrm{SP}}\right)$ with observer (solid blue line) and with state estimation performed by an open-loop model (dashed green line).

SH regulation performance: the maximum error is more than $8 \mathrm{~K}$ in this case, while it is about $5 \mathrm{~K}$ when the observer is used. Thus, observer was found to improve the robustness of the model-based control strategy. This would allow to reduce the SH set point and thus, once again, increase cycle efficiency while keeping the same safety margins.

\section{CONCLUSION}

Effective SH control is a key issue when controlling an ORC system for engine WHR. In this paper, the control design for an ORC with a kinetic turbine has been presented and assessed.

The baseline strategy for $\mathrm{SH}$ regulation was improved by combining a dynamic feedforward term to a commonly used gain-scheduled PID approach. The robustness of the feedforward term computation (based on model inversion) has been demonstrated, allowing a real-time implementation. Experimental results, representative of a long-haul truck mission, illustrate the enhanced performance in terms of disturbance rejection.

This approach has been extended to the multivariable case, with the use of the evaporator bypass as an additional actuator, providing the possibility to track a second variable (a pressure set point) while maintaining the previous $\mathrm{SH}$ regulation performance. The proposed scheme combines an additional nonlinear controller to an implicit EKF for wall temperature estimation. This opens up the possibility to implement a two-level closed-loop control strategy [19], [23], where an energy management system would provide set points to a low-level controller.

Future work will be directed toward the experimental assessment of the overall strategy, combining the low-level controller proposed herein with the above-mentioned energy management system.

\section{APPENDIX}

\section{PROOF OF PROPOSITION 1}

Since $\varphi=1-L_{1}-L_{2}-L_{3}$, to prove that $(\partial \varphi / \partial p)<0$, it suffices to prove the following conditions:

1) $\left(\partial L_{3} / \partial p\right)>0$, 2) $\left(\partial L_{2} / \partial p\right)>0$, 3) $\left(\partial L_{1} / \partial p\right)>0$.

1) From the algebraic system (7), the following equation is deduced:

$$
L_{3}=\frac{N_{3}}{D_{3}}
$$

with

$$
\begin{aligned}
N_{3} & =C_{d} S_{\text {turb }}(2 \rho(p, \mathrm{SH}) p)^{1 / 2}\left[h_{\text {out }}(p, \mathrm{SH})-h_{v}(p)\right] \\
D_{3} & =S_{f} \alpha_{3}\left[T_{w, 3}-T_{f, 3}(p, \mathrm{SH})\right] .
\end{aligned}
$$
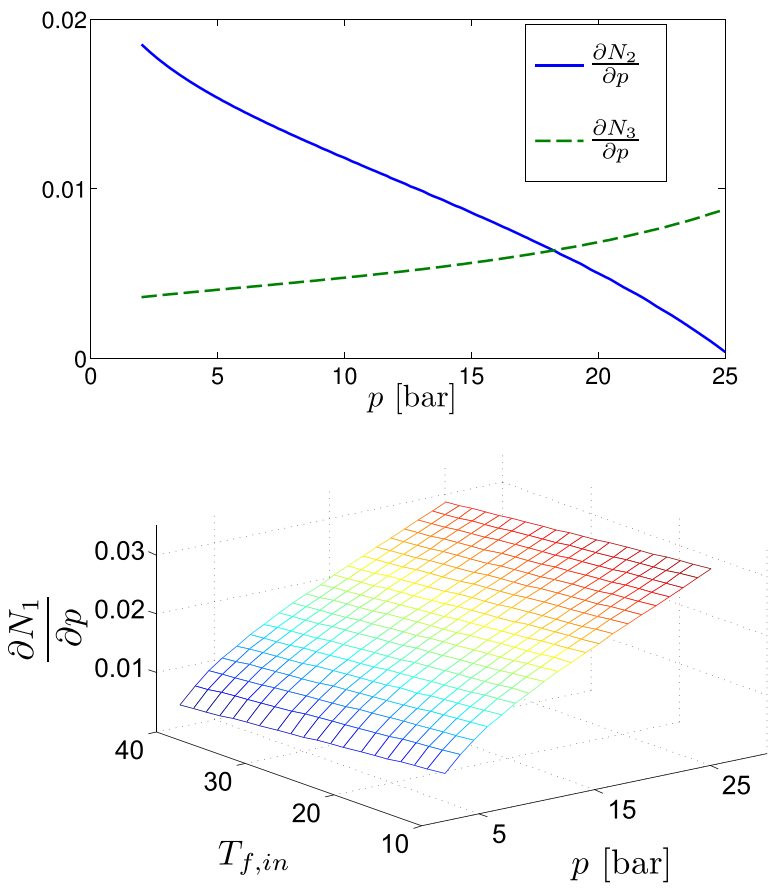

Fig. 18. Functions $N_{1}, N_{2}$, and $N_{3}$ increase with pressure $p$, for the considered working fluid $\mathrm{R} 245 \mathrm{fa}$ and $\mathrm{SH}=30 \mathrm{~K}$.

Hence, $\left(\partial L_{3} / \partial p\right)$ is strictly positive if the condition

$$
\left(\partial N_{3} / \partial p\right) D_{3}-N_{3}\left(\partial D_{3} / \partial p\right)>0
$$

holds. Since, in the superheated vapor condition, the enthalpy $h_{\text {out }}$ at the evaporator outlet is greater than the saturation enthalpy $h_{v}$, and it comes that $N_{3}>0$. Also, the temperature $T_{f, 1}$ increases with the pressure $p$, yielding $\left(\partial D_{3} / \partial p\right)<0$. Moreover from $(8 \mathrm{c})$ of Assumption 1, $D_{3}>0$. Finally, Fig. 18(a) shows that $\left(\partial N_{3} / \partial p\right)>0$ for the considered pressure range. So $\left(\partial L_{3} / \partial p\right)>0$.

2) We have

$$
L_{2}=\frac{N_{2}}{D_{2}}
$$

with $N_{2}=C_{d} S_{\text {turb }}(2 \rho(p, \mathrm{SH}) p)^{1 / 2}\left[h_{v}(p)-h_{l}(p)\right]$ and $D_{2}=S_{f} \alpha_{2}\left[T_{w, 2}-T_{f, 2}(p, t)\right]$. From similar arguments than in 1), it can be deduced that $N_{2}>0$, $\left(\partial D_{2} / \partial p\right)<0$, and $D_{2}>0$. Finally, Fig. 18(a) shows that $\left(\partial N_{2} / \partial p\right)>0$. So $\left(\partial L_{2} / \partial p\right)>0$.

3) We have

$$
L_{1}=\frac{N_{1}}{D_{1}}
$$

with $N_{1}=C_{d} S_{\text {turb }}(2 \rho(p, \mathrm{SH}) p)^{1 / 2}\left[h_{l}(p)-h_{\text {in }}\right]$ and $D_{1}=S_{f} \alpha_{1}\left[T_{w, 1}-T_{f, 1}(p, t)\right]$. From similar arguments than in 1$)$, it follows that $N_{1}>0,\left(\partial D_{1} / \partial p\right)<0$, and $D_{1}>0$. Notice that the working fluid temperature $T_{f, 1}$ also depends on the (disturbance) value of the working fluid temperature at evaporator inlet. Finally, Fig. 18(b) shows that $\left(\partial N_{1} / \partial p\right)>0$ for considered pressure and disturbance range. So $\left(\partial L_{2} / \partial p\right)>0$. 


\section{REFERENCES}

[1] D. W. Stanton, "Systematic development of highly efficient and clean engines to meet future commercial vehicle greenhouse gas regulations," SAE Int. J. Engines, vol. 6, no. 3, pp. 1395-1480, 2013.

[2] T. Howell, "Development of an ORC system to improve HD truck fuel efficiency," in Proc. DEER Conf., 2011, pp. 1-21.

[3] T. A. Horst, H.-S. Rottengruber, M. Seifert, and J. Ringler, "Dynamic heat exchanger model for performance prediction and control system design of automotive waste heat recovery systems," Appl. Energy, vol. 105, pp. 293-303, May 2013. [Online]. Available: http://www.sciencedirect.com/science/article/pii/S0306261912009518

[4] T. A. Horst, W. Tegethoff, P. Eilts, and J. Koehler, "Prediction of dynamic Rankine cycle waste heat recovery performance and fuel saving potential in passenger car applications considering interactions with vehicles' energy management," Energy Convers. Manage., vol. 78, pp. 438-451, Feb. 2014. [Online]. Available: http://www. sciencedirect.com/science/article/pii/S0196890413007097

[5] T. Endo et al., "Study on maximizing exergy in automotive engines," SAE Tech. Paper 2007-01-0257, 2007. [Online]. Available: http://dx.doi.org/10.4271/2007-01-0257

[6] Q. Hussain and D. Brigham, "Organic Rankine cycle for light duty passenger vehicles," in Proc. DEER Conf., 2011, pp. 1-14.

[7] C. Nelson, "Exhaust energy recovery," in Proc. DEER Conf., 2009, pp. $4-7$.

[8] R. W. Kruiswyk, "An engine system approach to exhaust waste heat recovery," in Proc. DEER Conf., 2010, pp. 1-31.

[9] R. Aneja, S. Singh, K. Sisken, R. Dold, and H. Oelschlegel, "Exhaust heat driven Rankine cycle for a heavy duty diesel engine," in Proc. DEER Conf., 2011, pp. 1-16.

[10] N. Espinosa, I. Gil-Roman, D. Didiot, V. Lemort, B. Lombard, and S. Quoilin, "Transient organic Rankine cycle modelling for waste heat recovery on a truck," in Proc. 24th Int. Conf. Efficiency, Cost, Optim., Simulation Environ. Impact Energy Syst., 2011, pp. 1-21.

[11] C. Nelson, "Exhaust energy recovery," in Proc. FY2006 Аnпи. Prog. Rep. Adv. Combustion Engine Technol., 2009, pp. 247-250.

[12] C. Sprouse, III, and C. Depcik, "Review of organic Rankine cycles for internal combustion engine exhaust waste heat recovery," Appl. Thermal Eng., vol. 51, nos. 1-2, pp. 711-722, 2013. [Online]. Available: http://www.sciencedirect.com/science/article/pii/S1359431112006734

[13] H. Teng, J. Klaver, T. Park, G. Hunter, and B. van der Velde, "A Rankine cycle system for recovering waste heat from HD diesel engines-WHR system development," SAE Tech. Paper 2011-01-0311, 2011. [Online]. Available: http://dx.doi.org/10.4271/2011-01-0311

[14] A. Boretti, "Recovery of exhaust and coolant heat with R245fa organic Rankine cycles in a hybrid passenger car with a naturally aspirated gasoline engine," Appl. Thermal Eng., vol. 36, pp. 73-77, Apr. 2012. [Online]. Available: http://www.sciencedirect.com/science/ article/pii/S1359431111006880

[15] V. Grelet, T. Reiche, V. Lemort, M. Nadri, and P. Dufour, "Transient performance evaluation of waste heat recovery Rankine cycle based system for heavy duty trucks," Appl. Energy, vol. 165, pp. 878-892, Mar. 2016.

[16] T. Park, H. Teng, G. Hunter, B. van der Velde, and J. Klaver, "A Rankine cycle system for recovering waste heat from HD diesel enginesExperimental results," SAE Tech. Paper 2011-01-1337, 2011. [Online]. Available: http://dx.doi.org/10.4271/2011-01-1337

[17] F. Merz, A. Sciarretta, J.-C. Dabadie, and L. Serrao, "On the optimal thermal management of hybrid-electric vehicles with heat recovery systems," Oil Gas Sci. Technol.-Revue d'IFP Energies Nouvelles, vol. 67, no. 4, pp. 601-612, 2012.

[18] F. Willems, F. Kupper, and R. Cloudt, "Integrated energy \& emission management for heavy-duty diesel engines with waste heat recovery system," IFAC Proc. Vol., vol. 45, no. 30, pp. 270-277, 2012.

[19] J. Peralez, P. Tona, M. Nadri, P. Dufour, and A. Sciarretta, "Optimal control for an organic Rankine cycle on board a diesel-electric railcar," J. Process Control, vol. 33, pp. 1-13, Sep. 2015. [Online]. Available: http://www.sciencedirect.com/science/article/pii/S0959152415000554

[20] G. Hou, R. Sun, G. Hu, and J. Zhang, "Supervisory predictive control of evaporator in organic Rankine cycle (ORC) system for waste heat recovery," in Proc. Int. Conf. Adv. Mech. Syst. (ICAMechS), Aug. 2011, pp. $306-311$.

[21] J. Zhang, W. Zhang, G. Hou, and F. Fang, "Dynamic modeling and multivariable control of organic Rankine cycles in waste heat utilizing processes," Comput. Math. Appl., vol. 64, no. 5, pp. 908-921, 2012. [Online]. Available: http://www.sciencedirect.com/ science/article/pii/S0898122112000752
[22] J. Zhang, Y. Zhou, S. Gao, and G. Hou, "Constrained predictive control based on state space model of organic Rankine cycle system for waste heat recovery," in Proc. Chin. Control Decision Conf. (CCDC), 2012, pp. 230-234.

[23] S. Quoilin, R. Aumann, A. Grill, A. Schuster, V. Lemort, and H. Spliethoff, "Dynamic modeling and optimal control strategy of waste heat recovery organic Rankine cycles," Appl. Energy, vol. 88, no. 6, pp. 2183-2190, 2011.

[24] X.-D. He, S. Liu, and H. H. Asada, "Modeling of vapor compression cycles for multivariable feedback control of HVAC systems," ASME J. Dyn. Syst., Meas., Control, vol. 119, no. 2, pp. 183-191, 1997.

[25] B. P. Rasmussen and A. G. Alleyne, "Control-oriented modeling of transcritical vapor compression systems," ASME J. Dyn. Syst., Meas., Control, vol. 126, no. 1, pp. 54-64, 2004.

[26] A. Alleyne, B. Rasmussen, M. Keir, and B. Eldredge, "Advances in energy systems modeling and control," in Proc. IEEE Amer. Control Conf. (ACC), Jul. 2007, pp. 4363-4373.

[27] B. Rasmussen and A. Alleyne, "Gain scheduled control of an air conditioning system using the Youla parameterization," IEEE Trans. Control Syst. Technol., vol. 18, no. 5, pp. 1216-1225, Sep. 2010.

[28] J. Peralez et al., "Improving the control performance of an organic Rankine cycle system for waste heat recovery from a heavy-duty diesel engine using a model-based approach," in Proc. 52nd IEEE Conf. Decision Control (CDC), Dec. 2013, pp. 6830-6836.

[29] J. Peralez, M. Nadri, P. Dufour, P. Tona, and A. Sciarretta, "Control design for an automotive turbine Rankine cycle system based on nonlinear state estimation," in Proc. 53rd IEEE Conf. Decision Control (CDC), Dec. 2014, pp. 3316-3321.

[30] J. Bao and L. Zhao, "A review of working fluid and expander selections for organic Rankine cycle," Renew. Sustain. Energy Rev., vol. 24, pp. 325-342, Aug. 2013. [Online]. Available: http://www. sciencedirect.com/science/article/pii/S1364032113001998

[31] D. Wei, X. Lu, Z. Lu, and J. Gu, "Dynamic modeling and simulation of an organic Rankine cycle (ORC) system for waste heat recovery," Appl. Thermal Eng., vol. 28, no. 10, pp. 1216-1224, 2008. [Online]. Available: http://www.sciencedirect.com/science/article/pii/S1359431107002633

[32] S. H. Kang, "Design and experimental study of ORC (organic Rankine cycle) and radial turbine using R245fa working fluid," Energy, vol. 41, no. 1, pp. 514-524, 2012. [Online]. Available: http://www. sciencedirect.com/science/article/pii/S0360544212001302

[33] E. Feru et al., "Experimental validation of a dynamic waste heat recovery system model for control purposes," SAE Tech. Paper 2013-01-1647, 2013. [Online]. Available: http://dx.doi.org/10.4271/2013-01-1647

[34] D. Luong and T.-C. Tsao, "Linear quadratic integral control of an organic Rankine cycle for waste heat recovery in heavy-duty diesel powertrain," in Proc. IEEE Amer. Control Conf. (ACC), Jun. 2014, pp. 3147-3152.

[35] E. Feru, F. Willems, B. de Jager, and M. Steinbuch, "Model predictive control of a waste heat recovery system for automotive diesel engines," in Proc. 18th Int. Conf. Syst. Theory, Control Comput. (ICSTCC), Oct. 2014, pp. 658-663.

[36] J. Peralez, P. Tona, A. Sciarretta, P. Dufour, and M. Nadri, "Towards model-based control of a steam Rankine process for engine waste heat recovery," in Proc. IEEE Vehicle Power Propuls. Conf. (VPPC), Oct. 2012, pp. 289-294.

[37] B. P. Rasmussen and A. G. Alleyne, "Dynamic modeling and advanced control of air conditioning and refrigeration systems," Ph.D. dissertation, Dept. Mech. Sci. Eng., Univ. Illinois Urbana-Champaign, Champaign, IL, USA, 2005.

[38] T. Yamamoto, T. Furuhata, N. Arai, and K. Mori, "Design and testing of the organic Rankine cycle," Energy, vol. 26, no. 3, pp. 239-251, 2001. [Online]. Available: http://www.sciencedirect.com/science/article/ pii/S0360544200000633

[39] K. H. Ang, G. Chong, and Y. Li, "PID control system analysis, design, and technology," IEEE Trans. Control Syst. Technol., vol. 13, no. 4, pp. 559-576, Jul. 2005.

[40] P. Tona, J. Peralez, and A. Sciarretta, "Supervision and control prototyping for an engine exhaust gas heat recovery system based on a steam Rankine cycle," in Proc. IEEE/ASME Int. Conf. Adv. Intell. Mechatronics (AIM), Jul. 2012, pp. 695-701.

[41] H. Hammouri and M. Nadri, "An observer design for a class of implicit systems," Syst. Control Lett., vol. 62, no. 3, pp. 256-261, 2013. [Online]. Available: http://www.sciencedirect.com/science/article/ pii/S0167691112002125

[42] D. Luong, "Modeling, estimation, and control of waste heat recovery systems," Ph.D. dissertation, Dept. Eng., Univ. California, Los Angeles, Los Angeles, CA, USA, 2013. 
[43] R. Nikoukhah, "A new methodology for observer design and implementation," IEEE Trans. Autom. Control, vol. 43, no. 2, pp. 229-234, Feb. 1998.

[44] G. Besançon, Nonlinear Observers and Applications. Berlin, Germany: Springer-Verlag, 2007.

[45] J. Åslund and E. Frisk, "An observer for non-linear differential-algebraic systems," Automatica, vol. 42, no. 6, pp. 959-965, 2006.

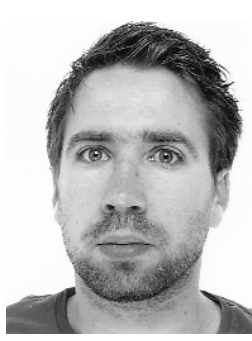

Johan Peralez received the M.Sc. and Ph.D. degrees in systems and controls from the Lyon University of Science, Lyon, France, in 2011 and 2015, respectively. His thesis work, conducted in part within IFP, Rueil-Malmaison, France, Energies Nouvelles, Rueil-Malmaison, focused on Rankine cycle aboard vehicles.

He was a Post-Doctoral Researcher with the Laboratoire d'Automatique et de Génie des Procédés Laboratory, Villeurbanne, France, from 2015 to 2016, where he was interested in triggered control theory.

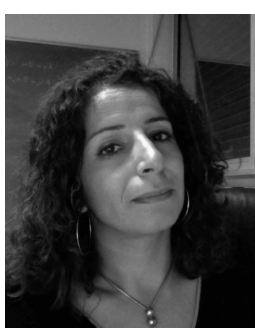

Madiha Nadri received the M.Sc. degree in automatic control and the Ph.D. degree from Université Claude Bernard Lyon 1 (UCBL1), Villeurbanne, France, in 1997 and 2001, respectively.

She was a Lecturer for one year. She joined the Division of Applied Mathematics and Process Control, IFP Energies Nouvelles, Rueil-Malmaison, France, as a Research Assistant. Since 2005, she has been an Assistant Professor of Automatic Control with the Department of Electrical and Chemical Engineering, UCBL1. Her current research interests include state estimation problems, nonlinear observers, identification, Lyapunov stability of nonlinear systems, and control theory applications, especially in biological systems and automotive applications.

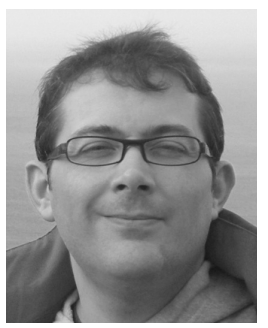

Pascal Dufour received the Ph.D. degree in automatic control from Université Claude Bernard Lyon 1 (UCBL1), Villeurbanne, France, in 2000.

He was a Post-Doctoral Fellow with the University of Delaware, Newark, DE, USA, from 2000 to 2001. Since 2001, he has been an Associate Professor with UCBL1. His current research interests include nonlinear systems, model-based control approach, model predictive control, observer-based closed loop identification, and optimization techniques, with applications in chemical engineering (drying, lyophilization, catalysis, curing, polymer processing, and Rankinebased waste heat recovery system for trucks).

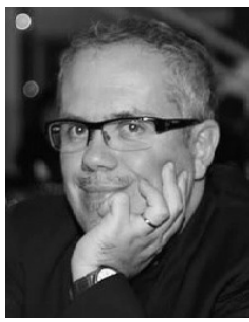

Paolino Tona received the Ph.D. degree in automatic control from the Institut National Polythecnique de Grenoble, Grenoble, France, in 2000.

$\mathrm{He}$ is currently a Research Engineer and Project Manager with IFP Energies Nouvelles, Rueil-Malmaison, France, a French public-sector research and innovation center, where he is currently leading the Control of Wave Energy Converters project. He has coordinated and/or collaborated with several projects in the fields of energies and transportation, such as the TRENERGY and TIGRE projects on waste heat recovery from exhaust gases on board vehicles, or the CITYBRID and MELODYS projects on hybrid electric trucks. His current research interests include model predictive control and, more generally, process control, system identification, engine and powertrain control, energy management, waste heat recovery, and control of wave energy converters.

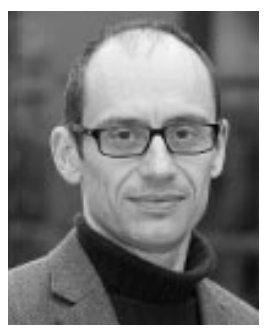

Antonio Sciarretta received the M.Sc. degree in mechanical engineering and the Ph.D. degree in thermal machines from the University of L'Aquila, L'Aquila, Italy, in 1995 and 1999, respectively, and the Habilitation degree in control engineering from the Grenoble Institute of Technology, Grenoble, France, in 2009.

After several teaching and research experiences in Italy and Switzerland, particularly, with ETH Zurich, Zürich, Switzerland, where he was a Lecturer until 2014, he joined the Control, Signals, and Systems Department, IFP Energies Nouvelles, Rueil-Malmaison, France, in 2006. Since 2009, he has been an IFPEN Expert of hybrid vehicles and energy management and the Titular of the Tuck foundation Chair on the same subject with the IFP School. He has actively contributed to the development of hybrid-vehicle activities with IFPEN, Rueil-Malmaison, France. He has co-authored the book entitled Vehicle Propulsion Systems (Springer) in three editions and contributes to the scientific and professional community as a Journal Associate Editor, Conference Organizer, and Project Evaluator. His current research interests include control and optimization for electrified vehicles and other energy systems. 